Review

\title{
Biochemical and Functional Insights into the Integrated Regulation of Innate Immune Cell Responses by Teleost Leukocyte Immune-Type Receptors
}

\author{
Chenjie Fei, Joshua G. Pemberton, Dustin M. E. Lillico, Myron A. Zwozdesky and \\ James L. Stafford * \\ Department of Biological Sciences, University of Alberta, Edmonton, Alberta, T6G 2E9, Canada; \\ chenjei@ualberta.ca (C.F.); jp28@ualberta.ca (J.G.P.); dlillico@ualberta.ca (D.M.E.L.); \\ zwozdesky@ualberta.ca (M.A.Z.) \\ * Correspondence: stafford@ualberta.ca; Tel.: +1-780-492-9258; Fax: +1-780-492-9234
}

Academic Editor: Brian Dixon

Received: 18 December 2015; Accepted: 1 March 2016; Published: 8 March 2016

\begin{abstract}
Across vertebrates, innate immunity consists of a complex assortment of highly specialized cells capable of unleashing potent effector responses designed to destroy or mitigate foreign pathogens. The execution of various innate cellular behaviors such as phagocytosis, degranulation, or cell-mediated cytotoxicity are functionally indistinguishable when being performed by immune cells isolated from humans or teleost fishes; vertebrates that diverged from one another more than 450 million years ago. This suggests that vital components of the vertebrate innate defense machinery are conserved and investigating such processes in a range of model systems provides an important opportunity to identify fundamental features of vertebrate immunity. One characteristic that is highly conserved across vertebrate systems is that cellular immune responses are dependent on specialized immunoregulatory receptors that sense environmental stimuli and initiate intracellular cascades that can elicit appropriate effector responses. A wide variety of immunoregulatory receptor families have been extensively studied in mammals, and many have been identified as cell- and function-specific regulators of a range of innate responses. Although much less is known in fish, the growing database of genomic information has recently allowed for the identification of several immunoregulatory receptor gene families in teleosts. Many of these putative immunoregulatory receptors have yet to be assigned any specific role(s), and much of what is known has been based solely on structural and/or phylogenetic relationships with mammalian receptor families. As an attempt to address some of these shortcomings, this review will focus on our growing understanding of the functional roles played by specific members of the channel catfish (Ictalurus punctatus) leukocyte immune-type receptors (IpLITRs), which appear to be important regulators of several innate cellular responses via classical as well as unique biochemical signaling networks.
\end{abstract}

Keywords: teleost; immunoregulatory receptors; channel catfish; leukocyte immune-type receptors; innate immunity; phagocytosis; intracellular signaling; functional plasticity; tyrosine-based signaling motifs

\section{Introduction}

Innate immune cells use a variety of receptor families to dynamically control the initiation, amplification, as well as termination of effector responses [1,2]. In general, immunoregulatory receptors are expressed at the cell surface and communicate extracellular stimuli to sophisticated, yet highly conserved, intracellular signaling networks that control potent antimicrobial functions $[1,2]$. 
The extracellular domains of each immunoregulatory receptor-type provide the interface for target recognition [3], whereas the transmembrane (TM) segments and cytoplasmic tail (CYT) regions translate binding events into a range of prototypical immune cell responses; characteristically, through a series of tyrosine-based signaling events [4]. Receptor-mediated signal transduction responses are vital for host protection from pathogens and, depending on the cell-type(s) activated and specific receptor(s) involved, include: degranulation, phagocytosis, cell-mediated cytotoxicity, and the production of bioactive molecules such as cytokines or various antimicrobial species.

Although it is well established that various teleost immune cell-types can execute the same range of effector responses that are performed by functional counterparts found in mammals, the specific immunoregulatory receptors and their associated signaling networks that control innate cellular defenses in fish remain unknown. For example, teleost immune cells can perform phagocytosis (macrophages and B cells) [5-9], cell-mediated cytotoxicity (Natural killer (NK)-like cells) [10-12], antigen presentation (macrophages) [13,14], and degranulation (mast cells and neutrophils) [15-17]. However, the immunoregulatory receptor systems controlling each of these important innate defenses have yet to be characterized in detail. In the past, these shortcomings were largely due to a lack of identified candidate genes, but the recent cloning and molecular characterization of an assortment of immune-related genes has significantly advanced our understanding of the immunoregulatory receptor families that exist in teleost fishes [18-20].

Many of the identified teleost receptors belong to the immunoglobulin superfamily (IgSF) and some of these share distant phylogenetic relationships and basic structural features with several mammalian immunoregulatory receptor families, including; Fc receptors (FcRs), FcR-like proteins (FcRLs), killer Ig-like receptors (KIRs), and leukocyte Ig-like receptors (LILRs). However, to date the orthologous relationships between the identified teleost genes and the known mammalian receptor sub-types remain to be established. One major factor that precludes defining orthology is the lack of identified ligands for teleost immunoregulatory receptors. Moreover, the discovery and characterization of novel immune-type receptors (NITRs) suggests that teleost immunity may also be in part regulated by unique receptor-types that are exclusive to bony fishes [21]. To our knowledge, teleost NITRs are not related to any immunoregulatory receptor families in amphibians, birds, or mammals; but, they do participate in NK cell-mediated allorecognition, implying they are the functional equivalents of mammalian NK receptors (NKRs) [22,23]. Further information regarding teleost NITRs can be found in [24-26]. Alternatively, teleost leukocyte immune-type receptors (LITRs), which were originally identified in the channel catfish (Ictalurus punctatus), do share distant phylogenetic relationships with several families of mammalian IgSF members including FcRs, FcRLs, and various NKRs encoded within the leukocyte receptor complex (LRC) [27]. Information regarding the discovery, phylogenetic analyses, predicted structures, expression patterns, and putative binding partners of LITRs are reported in [27,28]; which we have also recently reviewed [20]. In addition, Table 1 presents the results of updated database searches for IpLITR-like proteins in other vertebrates, which further reinforces that these teleost proteins are distantly related to human FcRLs, FcRs, LILRs, KIRs, sialic acid-binding Ig-type lectins (Siglecs), carcinoembryonic antigen-related cell adhesion molecules (CEACAMs) as well as several IgSF members in rodents, birds, and frogs. It appears likely that the Ig-like domains contained within IpLITRs maintain some basal signatures of an ancestral IgSF that has since diversified throughout vertebrate evolution to become receptors involved in a broad range of vital immunoregulatory functions including antibody-binding, self- and non-self recognition, adhesion, and pathogen detection. Determining which of these important immunoregulatory functions, if any, are controlled by members of the IpLITR family will require further investigations. However, the fact that human immunoregulatory receptor sequences such as FcR/FcRLs, LILRs, and KIRs retrieve IpLITRs as the top matching sequences from basic local alignment search tool (BLAST) analyses indicates that IpLITRs are related to these various mammalian immune proteins. To further broaden the search for human immunoregulatory receptor-like sequences in additional fish species, selected protein sequences from Table 1 were also used in BLASTp searches against the teleost databases 
and representative matches from these searches are listed in Table 2. Although some of the human immunoregulatory receptor queries we used for searching the catfish databases did not retrieve any significant matches (i.e., Fc $\gamma$ RIIA, Fc $\gamma$ RIIB, PIGR, KIR2DL1, Siglec-4, etc.; see Table 1) they did identify matches in several other fishes (Table 2). However, it remains to be determined whether or not these teleost sequences identified by BLASTp are indeed the functional equivalents of the human immunoregulatory receptor queries. Furthermore, since fish have both teleost-specific receptor families (i.e., NITRs) and those that are distantly related to various mammalian immunoregulatory receptors belonging to the IgSF (i.e., LITRs), it remains a formidable challenge to determine the precise roles of all of these receptor-types in teleost immunity.

Over the past decade, research in our lab has focused on characterizing the biochemistry and functionality of Ictalurus punctatus (Ip)LITRs with an emphasis on understanding how putative stimulatory and inhibitory receptor sub-types engage intracellular signaling responses to regulate immune cell actions. These efforts have revealed some expected, as well as unexpected details regarding IpLITR-mediated signaling events and their concomitant regulation of cellular immunity. By designing constructs that allow for the expression of IpLITRs in mammalian cells, we have taken advantage of epitope-tagging technology and commercially-available antibodies (Abs) to easily trigger these receptors in the absence of natural ligands and without developing IpLITR-specific monoclonal (m)Abs. Receptor chimeras that link the CYT regions of IpLITRs with the extracellular domains of mammalian receptors (i.e., KIRs) have also allowed us to promote IpLITR-based signaling events using ligand-expressing target cells. Both of these strategies have assisted in defining key aspects of the stimulatory and inhibitory actions of IpLITRs as well as defining their unexpected functional versatility. It is important to qualify that our results do rely on heterologous expression of fish immunoregulatory proteins in surrogate, but well-characterized, mammalian cell systems. The interpretations made from the data collected from these types of experiments should always be considerate of this fact. Although this experimental strategy is not adequate for informing the actual in vivo activities of IpLITRs, our work represents the most detailed biochemical and functional examination of teleost immunoregulatory receptors to date. It is clear from our studies that IpLITRs are likely potent effectors of immune cell signaling and that they have the potential to regulate various innate cellular responses including NK cell-mediated killing, phagocytosis, degranulation, and cytokine secretion. Here we will review, in detail, the characterization of putative stimulatory and inhibitory IpLITR sub-types and provide frameworks for understanding the concept of IpLITR functional plasticity; a concept that has also emerged for several mammalian immunregulatory receptor-types. 
Table 1. Protein basic local alignment search tool (BLASTp) searches for vertebrate immunoregulatory receptor-like sequences and intracellular signaling proteins in the Channel catfish (Ictalurus punctatus).

\begin{tabular}{|c|c|c|c|c|c|c|}
\hline Human FcRLs & Top Matching Catfish Sequences & E value & Score & ID & Pos. & Coverage \\
\hline FcRL6 (XP_005245185) & FcRI (NP_001187150) & $4 \mathrm{e}-09$ & 55.8 & $26 \%$ & $37 \%$ & $89 \%$ \\
\hline FcRL5 (AAK31327) & LITR TS32.15 L2.1a (ABI23564) & $1 \mathrm{e}-19$ & 165 & $26 \%$ & $40 \%$ & $90 \%$ \\
\hline FcRL4 (NP_112572) & LITR TS32.15 L2.2c (ABI23567) & $3 e-11$ & 63.2 & $25 \%$ & $38 \%$ & $89 \%$ \\
\hline FcRL3 (NP_443171) & LITR TS32.15 L1.1a (ABI16036) & $1 \mathrm{e}-18$ & 88.2 & $25 \%$ & $39 \%$ & $90 \%$ \\
\hline FcRL2 (NP_110391) & LITR TS32.17 L2.1a (ABI23578) & $6 e-06$ & 46.2 & $24 \%$ & $39 \%$ & $79 \%$ \\
\hline FcRL1 (NP_443170) & Hepacam 2 (NP_00118775) & $2 \mathrm{e}-04$ & 40.8 & $23 \%$ & $46 \%$ & $38 \%$ \\
\hline Human FcRs & Top Matching Catfish Sequences & E value & Score & ID & Pos. & Coverage \\
\hline \multirow[t]{2}{*}{ FcyRI (NP_000557) } & FcRI (NP_001187150) & $2 \mathrm{e}-17$ & 79.0 & $26 \%$ & $40 \%$ & $96 \%$ \\
\hline & LITR TS32.15 L1.1a (ABI16036) & $2 \mathrm{e}-11$ & 62.4 & $26 \%$ & $40 \%$ & $50 \%$ \\
\hline FceRI $\alpha\left(X P \_003821022\right)$ & LITR TS32.17 L1.1a (ABI16049) & $2 \mathrm{e}-07$ & 48.5 & $29 \%$ & $43 \%$ & $96 \%$ \\
\hline Fc $\gamma$ RIIA (NP_001129691) & - no matches- & - & - & - & - & - \\
\hline Fc $\gamma$ RIIIA (NP_001121068) & LITR TS32.15 L2.1a (ABI23564) & $1 \mathrm{e}-07$ & 49.7 & $25 \%$ & $44 \%$ & $77 \%$ \\
\hline Fc $\gamma$ RIIC (NP_963857) & - no matches- & - & - & - & - & - \\
\hline Fc $\gamma$ RIIIB (NP_001231682) & LITR TS32.15 L2.1a (ABI23564) & $1 \mathrm{e}-05$ & 44.3 & $25 \%$ & $44 \%$ & $66 \%$ \\
\hline Fc $\gamma$ RIIB (NP_001002274) & - no matches- & - & - & - & - & - \\
\hline Fc $\mu \mathrm{R}(\mathrm{AAP} 36498)$ & -no matches- & - & - & - & - & - \\
\hline PIGR (NP_002635) & - no matches- & - & - & - & - & - \\
\hline Fc $\alpha \mu R\left(N P \_114418\right)$ & - no matches- & - & - & - & - & - \\
\hline Human LRC Proteins & Top Matching Catfish Sequences & E value & Score & ID & Pos. & Coverage \\
\hline Fc $\alpha R$ (NP_001991) & - no matches- & - & - & - & - & - \\
\hline NKp46 (O76036) & - no matches- & - & - & - & - & - \\
\hline LAIR1 (NP_001275954) & -no matches- & - & - & - & - & - \\
\hline LILRB1 (AAC51179) & LITR1 (AAW82352) & $6 e-10$ & 98.2 & $25 \%$ & $39 \%$ & $66 \%$ \\
\hline LILRB2 (XP_011546934) & LITR TS32.15 L2.2c (ABI23567) & $9 e-13$ & 68.6 & $23 \%$ & $38 \%$ & $85 \%$ \\
\hline LILRB3 (O75022) & LITR1 (AAW82352) & $4 \mathrm{e}-07$ & 50.4 & $23 \%$ & $39 \%$ & $73 \%$ \\
\hline LILRB4 (NP_001265355) & -no matches- & - & - & - & - & - \\
\hline
\end{tabular}


Table 1. Cont

\begin{tabular}{|c|c|c|c|c|c|c|}
\hline Human LRC Proteins & Top Matching Catfish Sequences & E value & Score & ID & Pos. & Coverage \\
\hline LILRB5 (NP_006831) & LITR1 (AAW82352) & $2 \mathrm{e}-10$ & 60.8 & $24 \%$ & $38 \%$ & $66 \%$ \\
\hline LILRA1 (NP_006854) & LITR TS32.15 L2.2c (ABI23567) & $2 \mathrm{e}-10$ & 61.2 & $24 \%$ & $38 \%$ & $89 \%$ \\
\hline LILRA2 (XP_011545392) & LITR1 (AAW82352) & $2 e-13$ & 70.1 & $24 \%$ & $38 \%$ & $66 \%$ \\
\hline LILRA3 (Q8N6C8) & LITR TS32.17 L1.2b (ABII6052) & $4 \mathrm{e}-09$ & 55.5 & $24 \%$ & $40 \%$ & $53 \%$ \\
\hline LILRA4 (P59901) & LITR1 (AAW82352) & $2 \mathrm{e}-08$ & 54.7 & $26 \%$ & $40 \%$ & $65 \%$ \\
\hline LILRA5 (A6NI73) & -no matches- & - & - & - & - & - \\
\hline LILRA6 (AGZ61988) & LITR1 (AAW82352) & $1 \mathrm{e}-09$ & 51.2 & $23 \%$ & $38 \%$ & $68 \%$ \\
\hline KIR3DL1 (ADM64608) & LITR3 (NP_001187136) & $7 e-08$ & 52.4 & $27 \%$ & $41 \%$ & $65 \%$ \\
\hline KIR3DS1 (ABX88987) & LITR3 (NP_001187136) & $8 \mathrm{e}-07$ & 48.9 & $27 \%$ & $41 \%$ & $65 \%$ \\
\hline KIR2DL1 (AAC50335) & -no matches- & - & - & - & - & - \\
\hline KIR2DS1 (XP_011546300) & - no matches- & - & - & - & - & - \\
\hline KIR2DL4 (ABW73959) & - no matches- & - & - & - & - & - \\
\hline Human Siglecs & Top Matching Catfish Sequences & E value & Score & ID & Pos. & Coverage \\
\hline Siglec-1 (Q9BZZ2) & LITR3 (NP_001187136) & $2 \mathrm{e}-16$ & 137 & $25 \%$ & $39 \%$ & $51 \%$ \\
\hline Siglec-2 (NP_001762) & LITR TS32.15 L1.1a (ABI16036) & $7 e-18$ & 170 & $26 \%$ & $40 \%$ & $74 \%$ \\
\hline Siglec-3 (P20138) & -no matches- & - & - & - & - & - \\
\hline Siglec-4 (NP_002352) & - no matches- & - & - & - & - & - \\
\hline Siglec-15 (Q6ZMC9) & - no matches- & - & - & - & - & - \\
\hline Human CEACAMs & Top Matching Catfish Sequences & E value & Score & ID & Pos. & Coverage \\
\hline \multirow[t]{2}{*}{ Ceacam-1 (NP_001703) } & Hepacam 2 (NP_00118775) & $4 \mathrm{e}-14$ & 144 & $31 \%$ & $44 \%$ & $64 \%$ \\
\hline & LITR3 (NP_001187136) & $1 e-09$ & 58.5 & $24 \%$ & $43 \%$ & $65 \%$ \\
\hline Ceacam-3 (NP_291021) & Hepacam 2 (NP_00118775) & $9 e-11$ & 59.3 & $31 \%$ & $50 \%$ & $56 \%$ \\
\hline Ceacam-4 (NP_001808) & - no matches- & - & - & - & - & - \\
\hline Ceacam-5 (NP_001295327) & LITR3 (NP_001187136) & $1 \mathrm{e}-22$ & 166 & $25 \%$ & $41 \%$ & $75 \%$ \\
\hline \multirow[t]{2}{*}{ Ceacam-6 (P40199) } & Hepacam 2 (NP_00118775) & $4 \mathrm{e}-14$ & 71.2 & $31 \%$ & $47 \%$ & $48 \%$ \\
\hline & LITR TS32.17 L2.2b (ABI23581) & $3 e-09$ & 56.2 & $27 \%$ & $41 \%$ & $56 \%$ \\
\hline Ceacam-7 (Q14002) & Hepacam 2 (NP_00118775) & $2 \mathrm{e}-07$ & 49.7 & $36 \%$ & $52 \%$ & $32 \%$ \\
\hline \multirow[t]{2}{*}{ Ceacam-8 (NP_001807) } & Hepacam 2 (NP_00118775) & $6 e-10$ & 58.5 & $27 \%$ & $42 \%$ & $51 \%$ \\
\hline & LITR TS32.15 L2.3b (ABI23569) & $2 \mathrm{e}-08$ & 53.1 & $28 \%$ & $42 \%$ & $56 \%$ \\
\hline
\end{tabular}


Table 1. Cont.

\begin{tabular}{|c|c|c|c|c|c|c|}
\hline Mouse PIRs & Top Matching Catfish Sequences & E value & Score & ID & Pos. & Coverage \\
\hline PIRA (NP_035217) & LITR TS32.15 L1.1a (ABI16036) & $1 \mathrm{e}-12$ & 61.6 & $24 \%$ & $39 \%$ & $88 \%$ \\
\hline PIRB (AAC53219) & LITR TS32.15 L1.1a (ABI16036) & $1 \mathrm{e}-11$ & 105 & $24 \%$ & $39 \%$ & $92 \%$ \\
\hline Chicken Receptors & Top Matching Catfish Sequences & E value & Score & ID & Pos. & Coverage \\
\hline FcRL1-like (XP_015135539) & LITR TS32.17 L2.1a (ABI23578) & $2 \mathrm{e}-06$ & 46.6 & $26 \%$ & $43 \%$ & $73 \%$ \\
\hline \multirow[t]{2}{*}{ FcRL2-like (NP_001090998) } & IpFcRI (NP_001187150) & $4 \mathrm{e}-21$ & 91.3 & $24 \%$ & $43 \%$ & $65 \%$ \\
\hline & LITR3 (NP_001187136) & $3 e-11$ & 63.2 & $25 \%$ & $41 \%$ & $69 \%$ \\
\hline CHIR-A (AAG37067) & LITR TS32.17 L2.1a (ABI23578) & $5 e-09$ & 53.9 & $28 \%$ & $45 \%$ & $75 \%$ \\
\hline CHIR-B (AAG37068) & LITR1 (AAW82352) & $6 e-10$ & 101 & $27 \%$ & $42 \%$ & $83 \%$ \\
\hline CHIR-AB1 (NP_001139613) & LITR TS32.15 L2.2c (ABI23567) & $3 e-07$ & 79.7 & $30 \%$ & $46 \%$ & $78 \%$ \\
\hline Xenopus Receptors & Top Matching Catfish Sequences & E value & Score & ID & Pos. & Coverage \\
\hline \multirow[t]{2}{*}{ Fc $\gamma$ RI-L (XP_012809801) } & FCRI (NP_001187150) & $1 \mathrm{e}-18$ & 84.0 & $34 \%$ & $45 \%$ & $63 \%$ \\
\hline & LITR TS32.15 L2.2c (ABI23567) & $1 \mathrm{e}-12$ & 67.4 & $28 \%$ & $45 \%$ & $62 \%$ \\
\hline \multirow[t]{2}{*}{ FcR3-L (XP_012824905) } & FcRI (NP_001187150) & $6 e-17$ & 80.1 & $22 \%$ & $46 \%$ & $43 \%$ \\
\hline & LITR TS32.15 L2.3c (ABI23570) & $2 \mathrm{e}-15$ & 76.6 & $25 \%$ & $43 \%$ & $61 \%$ \\
\hline \multirow[t]{2}{*}{ FcR4-L (XP_012809008) } & FcRI (NP_001187150) & $4 \mathrm{e}-18$ & 83.2 & $21 \%$ & $44 \%$ & $58 \%$ \\
\hline & LITR TS32.15 L2.2c (ABI23567) & $6 e-15$ & 75.5 & $23 \%$ & $40 \%$ & $92 \%$ \\
\hline FcR5-L (XP_012825305) & LITR TS32.17 L2.1a (ABI23578) & $8 e-19$ & 89.7 & $25 \%$ & $44 \%$ & $41 \%$ \\
\hline ILR-1 (XP_002938564) & LITR TS32.17 L2.2b (ABI23581) & $2 \mathrm{e}-12$ & 102 & $28 \%$ & $44 \%$ & $67 \%$ \\
\hline ILR-2 (NP_001121201) & LITR TS32.17 L2.1a (ABI23578) & $3 e-12$ & 65.1 & $20 \%$ & $45 \%$ & $69 \%$ \\
\hline
\end{tabular}


Table 1. Cont.

\begin{tabular}{|c|c|c|c|c|c|c|}
\hline Human Signaling Proteins & Top Matching Catfish Sequences & E value & Score & ID & Pos. & Coverage \\
\hline c-Src (P12931) & Lymphocyte PTP (AJW77401) & 0.0 & 560 & $59 \%$ & $77 \%$ & $82 \%$ \\
\hline SYK $(\mathrm{P} 43405)$ & SYK (NP_998008) * & 0.0 & 863 & $67 \%$ & $77 \%$ & $98 \%$ \\
\hline PI3K p85 $\alpha$ (NP_852664) & PI3K p $85 \alpha(\mathrm{AHH} 41763)$ & 0.0 & 864 & $62 \%$ & $76 \%$ & $99 \%$ \\
\hline Csk (NP_004374) & Csk-like (AJW77401) & $3 e-105$ & 318 & $40 \%$ & $58 \%$ & $95 \%$ \\
\hline GRB2 (CAG467401) & GRB2 (NP_001187313) & $3 e-151$ & 421 & $91 \%$ & $95 \%$ & $100 \%$ \\
\hline Gab2 (BAA76737) & Gab2 (XP_692935) & 0.0 & 793 & $63 \%$ & $75 \%$ & $99 \%$ \\
\hline Nck1 (NP_001278928) & Nck1 (NP_001278928) * & 0.0 & 615 & $77 \%$ & $87 \%$ & $100 \%$ \\
\hline SHP-1 (AAA36610) & SHP-1-like (XP_009290704) * & 0.0 & 783 & $66 \%$ & $78 \%$ & $95 \%$ \\
\hline SHP-2 (BAA02740) & SHP-2-like (CBX19678) * & 0.0 & 1076 & $91 \%$ & $94 \%$ & $100 \%$ \\
\hline SHIP-1 (AAB49680) & SHIP-1 (AJK26904) & 0.0 & 1164 & $56 \%$ & $67 \%$ & $99 \%$ \\
\hline SH2D1A (NP_001108409) & SH2D1A (NP_001187495) & $2 \mathrm{e}-49$ & 155 & $64 \%$ & $76 \%$ & $89 \%$ \\
\hline Vav3 (EAW̄51251) & Vav3 (XP_009296581)* & 0.0 & 1173 & $68 \%$ & $80 \%$ & $100 \%$ \\
\hline Rac1 (NP_008839) & Rac1 (AD027935) & $4 e-136$ & 381 & $94 \%$ & $98 \%$ & $100 \%$ \\
\hline Cdc42 (AAM21109) & Cdc42 (NP_001188177) & $2 e-134$ & 377 & $96 \%$ & $97 \%$ & $100 \%$ \\
\hline RhoA (P61586) & RhoA-like (NP_001187623) & $2 \mathrm{e}-138$ & 387 & $95 \%$ & $98 \%$ & $100 \%$ \\
\hline \multirow[t]{2}{*}{ Wave2 (P61586) } & Wave3 (NP_001074059) * & $1 \mathrm{e}-104$ & 322 & $44 \%$ & $53 \%$ & $100 \%$ \\
\hline & Wave2 (NP_957375) * & $2 \mathrm{e}-104$ & 313 & $76 \%$ & $85 \%$ & $38 \%$ \\
\hline WASp (NP_000368) & WASp (NP_956232) * & $1 e-106$ & 327 & $54 \%$ & $69 \%$ & $59 \%$ \\
\hline N-WASp (BAA20128) & N-WASp (NP_001076475) * & $3 e-145$ & 428 & $75 \%$ & $85 \%$ & $53 \%$ \\
\hline
\end{tabular}

(A) The amino acid sequences listed in the left column were used as queries to search the non-redundant protein sequence database for catfishes (taxid:7995) by blastp at http:/ /blast.ncbi.nlm.nih.gov/Blast; (B) Other than the human signaling protein queries, all searches we performed using the predicted extracellular regions of the receptor sequences (i.e., predicted TM segments and CYT regions were excluded from the searches); (C) For each search result the Expect (E) value reported provides the overall significance of the match with lower values closer to zero being considered more significant. The score indicates quality of the alignment with a higher score associated with a better alignment. This value is calculated using a formula that considers alignment of similar or identical residues, as wells as gaps in the alignment; (D) The top matching Channel catfish sequences are listed in the second column from the left and those marked with an * represent queries that did not retrieve a match using catfishes (taxid:7995) but did retrieve a match using Danio (taxid:7954); (E) Only sequences with scores $>40.0$ are reported. 
Table 2. Protein BLAST searches for human immunoregulatory receptor-like sequences in teleost fishes.

\begin{tabular}{|c|c|c|c|c|c|c|}
\hline Human Receptors & Teleost Matches & E value & Score & ID & Pos. & Coverage \\
\hline \multirow[t]{5}{*}{ FcRL5 (AAK31327) } & Zebrafish CD22 (XP_009293714) & $3 e-46$ & 184 & $27 \%$ & $43 \%$ & $94 \%$ \\
\hline & Salmon Sialoadhesin-like (XP_009293614) & $3 e-46$ & 184 & $26 \%$ & $45 \%$ & $97 \%$ \\
\hline & Herring Sialoadhesin-like (XP_012675080) & $8 e-33$ & 316 & $30 \%$ & $45 \%$ & $96 \%$ \\
\hline & Cichlid CD22-like (XP_014269289) & $1 \mathrm{e}-32$ & 276 & $28 \%$ & $47 \%$ & $76 \%$ \\
\hline & Herring FcRL5 (XP_012678524) & $4 e-31$ & 261 & $25 \%$ & $40 \%$ & $94 \%$ \\
\hline \multirow[t]{5}{*}{ Fc $\gamma$ RI (NP_000557) } & Asian arowana FcRL5 (KPP56756) & $6 e-21$ & 98.2 & $29 \%$ & $44 \%$ & $91 \%$ \\
\hline & Trout unamed protien (CDQ78931) & $2 e-18$ & 88.6 & $27 \%$ & $44 \%$ & $81 \%$ \\
\hline & Salmon Fc $\gamma$ RI-like (ACN10126) & $4 \mathrm{e}-18$ & 88.2 & $28 \%$ & $42 \%$ & $81 \%$ \\
\hline & Catfish FcRI (NP_001187150) & $3 e-15$ & 79.0 & $26 \%$ & $40 \%$ & $96 \%$ \\
\hline & Catfish TS32.15 L1.1a (ABI16036) & $4 \mathrm{e}-09$ & 62.4 & $29 \%$ & $44 \%$ & $50 \%$ \\
\hline \multirow[t]{5}{*}{ Fc $\gamma$ RIIA (NP_001129691)* } & Herring FcRL5 (XP_012678524) & $7 e-10$ & 208 & $31 \%$ & $41 \%$ & $79 \%$ \\
\hline & Yellow Croaker Fc $\gamma$ RII-like (XP_010752023) & $9 e-10$ & 60.5 & $25 \%$ & $45 \%$ & $78 \%$ \\
\hline & Tilapia Fc $\gamma$ RIB-like (XP_013119926) & $2 \mathrm{e}-09$ & 59.7 & $37 \%$ & $54 \%$ & $41 \%$ \\
\hline & Mexican tetra CD22 (XP_015459483) & $3 e-09$ & 60.8 & $31 \%$ & $47 \%$ & $70 \%$ \\
\hline & Herring FcRL3 (XP_012675232) & $2 \mathrm{e}-08$ & 58.9 & $27 \%$ & $50 \%$ & $70 \%$ \\
\hline \multirow[t]{5}{*}{ Fc $\gamma$ RIIB (NP_001002274) * } & Yellow Croaker Fc $\gamma$ RII-like (XP_010752023) & $1 \mathrm{e}-11$ & 65.9 & $28 \%$ & $48 \%$ & $67 \%$ \\
\hline & Killifish unknown protein (XP_013889184) & $2 \mathrm{e}-10$ & 65.1 & $27 \%$ & $43 \%$ & $82 \%$ \\
\hline & Mexican tetra CD22 (XP_015459483) & $4 \mathrm{e}-10$ & 63.9 & $31 \%$ & $46 \%$ & $61 \%$ \\
\hline & Herring FcRL3 (XP_012675232) & $2 \mathrm{e}-09$ & 62.0 & $28 \%$ & $51 \%$ & $70 \%$ \\
\hline & Cichlid Fc $\gamma$ RII-like (XP_006808904) & $3 e-08$ & 58.2 & $28 \%$ & $42 \%$ & $76 \%$ \\
\hline \multirow[t]{3}{*}{ Fc $\mu R$ (AAP36498) * } & Damselfish unknown protein (XP_008286766) & $4 \mathrm{e}-06$ & 52.8 & $34 \%$ & $47 \%$ & $42 \%$ \\
\hline & Salmon CMRF35-like (XP_014058627) & $8 \mathrm{e}-06$ & 51.2 & $34 \%$ & $47 \%$ & $42 \%$ \\
\hline & Killifish PIGR-like (012722396) & $2 \mathrm{e}-05$ & 50.1 & $29 \%$ & $41 \%$ & $40 \%$ \\
\hline \multirow[t]{5}{*}{ PIGR (NP_002635) * } & Tilapia PIGR-like (XP_013123119) & $4 e-25$ & 115 & $27 \%$ & $44 \%$ & $67 \%$ \\
\hline & Yellow Croaker PIGR (KKF27361) & $1 \mathrm{e}-23$ & 111 & $25 \%$ & $39 \%$ & $81 \%$ \\
\hline & Medaka PIGR (XP_011484914) & $3 e-23$ & 262 & $28 \%$ & $44 \%$ & $72 \%$ \\
\hline & Carp PIGR (ADB97624) & $1 \mathrm{e}-18$ & 92.8 & $31 \%$ & $47 \%$ & $73 \%$ \\
\hline & Zebrafish PIGR (NP_001289179) & $7 e-18$ & 90.5 & $30 \%$ & $47 \%$ & $68 \%$ \\
\hline
\end{tabular}


Table 2. Cont

\begin{tabular}{|c|c|c|c|c|c|c|}
\hline Human Receptors & Teleost Matches & E value & Score & ID & Pos. & Coverage \\
\hline Fc $\alpha \mathbf{R}\left(N P \_001991\right) *$ & Cichlid unknown protein (XP_014265321) & $7 \mathrm{e}-05$ & 48.5 & $29 \%$ & $46 \%$ & $51 \%$ \\
\hline \multirow[t]{2}{*}{ NKp46 (O76036)* } & Atlantic molly CD276-like (XP_014823336) & $4 \mathrm{e}-05$ & 49.7 & $24 \%$ & $37 \%$ & $65 \%$ \\
\hline & Sailfin molly IgSF 1-like Rc (XP_014882122) & $4 \mathrm{e}-04$ & 46.6 & $24 \%$ & $38 \%$ & $69 \%$ \\
\hline LAIR1 (NP_001275954) * & - no matches- & - & - & - & - & - \\
\hline \multirow[t]{5}{*}{ LILRB1 (AAC51179) } & Pike DSCAM-like (XP_12987993) & $1 \mathrm{e}-15$ & 84.3 & $28 \%$ & $41 \%$ & $85 \%$ \\
\hline & Pike FcRL5 (XP_010867787) & $6 \mathrm{e}-14$ & 79.7 & $26 \%$ & $43 \%$ & $82 \%$ \\
\hline & Salmon IgSF 1-like Rc (XP_01401166) & $2 \mathrm{e}-11$ & 71.6 & $27 \%$ & $41 \%$ & $83 \%$ \\
\hline & Pike LILRA4-like (XP_012988338) & $4 \mathrm{e}-10$ & 64.3 & $28 \%$ & $44 \%$ & $42 \%$ \\
\hline & Cafish LITR1 (AAW82352) & $2 \mathrm{e}-09$ & 65.1 & $26 \%$ & $40 \%$ & $86 \%$ \\
\hline \multirow[t]{4}{*}{ LILRB4 (NP_001265355) * } & Cichlid IgSF 1-like Rc (XP_014267965) & $2 \mathrm{e}-11$ & 68.9 & $27 \%$ & $47 \%$ & $78 \%$ \\
\hline & Amazon molly PEACAM-like (XP_007571377) & $4 \mathrm{e}-07$ & 56.2 & $28 \%$ & $42 \%$ & $77 \%$ \\
\hline & Atlantic molly IgSF 1-like Rc (XP_014827576) & $1 \mathrm{e}-05$ & 51.6 & $29 \%$ & $45 \%$ & $78 \%$ \\
\hline & Yellow Croaker LILRA2-like (KKF09113) & $2 e-05$ & 51.2 & $31 \%$ & $45 \%$ & $64 \%$ \\
\hline \multirow[t]{5}{*}{ LILRA2 (XP_011545392) } & Trout unamed protien (CDQ78931) & $1 \mathrm{e}-12$ & 75.9 & $27 \%$ & $42 \%$ & $90 \%$ \\
\hline & Pike DSCAM-like (XP_12987993) & $5 e-12$ & 73.6 & $27 \%$ & $42 \%$ & $82 \%$ \\
\hline & Catfish LITR1 (AAW82352) & $4 \mathrm{e}-11$ & 70.1 & $24 \%$ & $38 \%$ & $66 \%$ \\
\hline & Mexican tetra FcRL5 (XP_015464057) & $8 e-11$ & 69.7 & $28 \%$ & $41 \%$ & $72 \%$ \\
\hline & Pike FcRL5 (XP_010867787) & $7 e-10$ & 66.7 & $27 \%$ & $42 \%$ & $77 \%$ \\
\hline \multirow[t]{4}{*}{ LILRA5 (A6NI73) * } & Pllatyfish IgSF 1-like Rc (XP_005816340) & $4 \mathrm{e}-06$ & 53.1 & $28 \%$ & $40 \%$ & $72 \%$ \\
\hline & Cichlid KIR2DL4-like (XP_005951820) & $4 \mathrm{e}-05$ & 48.9 & $35 \%$ & $48 \%$ & $40 \%$ \\
\hline & Cichlid Fc $\gamma$ RI-like (XP_014267764) & $6 e-05$ & 48.5 & $34 \%$ & $49 \%$ & $40 \%$ \\
\hline & Cichlid IgSF 1-like Rc (XP_014267965) & $3 e-04$ & 47.0 & $32 \%$ & $45 \%$ & $44 \%$ \\
\hline \multirow[t]{5}{*}{ KIR3DL1 (ADM64608) } & Asian arowana FcRL5 (KPP56756) & $1 \mathrm{e}-11$ & 70.5 & $25 \%$ & $42 \%$ & $63 \%$ \\
\hline & Salmon KIR3DL1-like (XP_014042396) & $2 \mathrm{e}-11$ & 69.7 & $30 \%$ & $43 \%$ & $85 \%$ \\
\hline & Cichlid IgSF 1-like Rc (XP_014267965) & $9 \mathrm{e}-08$ & 70.5 & $25 \%$ & $43 \%$ & $85 \%$ \\
\hline & Salmon KIR3DS1-like (XP_014043811) & $2 \mathrm{e}-07$ & 55.5 & $31 \%$ & $44 \%$ & $56 \%$ \\
\hline & Catfish LITR3 (NP_001187136) & $1 \mathrm{e}-05$ & 52.0 & $27 \%$ & $41 \%$ & $65 \%$ \\
\hline
\end{tabular}


Table 2. Cont

\begin{tabular}{|c|c|c|c|c|c|c|}
\hline Human Receptors & Teleost Matches & E value & Score & ID & Pos. & Coverage \\
\hline \multirow[t]{5}{*}{ KIR2DL1 (AAC50335) * } & Salmon KIR3DS1-like (XP_014043811) & $1 \mathrm{e}-05$ & 49.7 & $28 \%$ & $40 \%$ & $78 \%$ \\
\hline & Salmon KIR3DL1-like (XP_014042396) & $4 e-05$ & 49.3 & $28 \%$ & $40 \%$ & $78 \%$ \\
\hline & Salmon LILRA4-like (XP_014037968) & $8 e-05$ & 48.5 & $29 \%$ & $41 \%$ & $75 \%$ \\
\hline & Pike OSCAR-like (XP_012988534) & $1 \mathrm{e}-04$ & 47.8 & $29 \%$ & $44 \%$ & $81 \%$ \\
\hline & Pike DSCAM-like (XP_12987993) & $1 \mathrm{e}-04$ & 48.1 & $26 \%$ & $43 \%$ & $81 \%$ \\
\hline \multirow[t]{4}{*}{ Siglec-2 (NP_001762) } & Zebrafish CD22 (XP_009293714) & $8 \mathrm{e}-71$ & 738 & $30 \%$ & $45 \%$ & $99 \%$ \\
\hline & Cichlid CD22-like (XP_005755784) & $4 e-64$ & 221 & $33 \%$ & $52 \%$ & $67 \%$ \\
\hline & Tilapia CD22-like (XP_013132285) & $6 e-61$ & 218 & $30 \%$ & $46 \%$ & $85 \%$ \\
\hline & Trout unamed protien (CDQ84455) & $2 e-58$ & 212 & $31 \%$ & $47 \%$ & $86 \%$ \\
\hline \multirow[t]{4}{*}{ Siglec-4 (NP_002352) * } & Salmon Siglec-4 (MAG) (XP_014021122) & $4 e-154$ & 459 & $44 \%$ & $64 \%$ & $96 \%$ \\
\hline & Pike Siglec-4 (MAG) (XP_014021122) & $7 e-152$ & 454 & $43 \%$ & $63 \%$ & $96 \%$ \\
\hline & Black cod Siglec-4 (MAG) (XP_010788688) & $4 e-151$ & 452 & $44 \%$ & $63 \%$ & $96 \%$ \\
\hline & Tiger puffer Siglec-4 (MAG) (NP_001027876) & 2e-149 & 449 & $43 \%$ & $63 \%$ & $96 \%$ \\
\hline \multirow[t]{4}{*}{ Ceacam-3 (NP_291021) } & Herring Hemicentin-1-like (XP_012676907) & $1 \mathrm{e}-18$ & 90.5 & $34 \%$ & $52 \%$ & $65 \%$ \\
\hline & Cichlid CEACAM 5-like (XP_014266060) & $4 e-16$ & 82.8 & $33 \%$ & $53 \%$ & $82 \%$ \\
\hline & Salmon CEACAM 1-like (XP_014038441) & $1 \mathrm{e}-15$ & 79.3 & $33 \%$ & $52 \%$ & $55 \%$ \\
\hline & Medaka CEACAM 1-like (XP_011483887) & $5 e-15$ & 77.8 & $28 \%$ & $42 \%$ & $94 \%$ \\
\hline Ceacam-4 (NP_001808)* & -no matches- & - & - & - & - & - \\
\hline \multirow[t]{5}{*}{ Ceacam-5 (NP_001295327) } & Tongue sole CEACAM 5-like (XP_008322222) & $4 \mathrm{e}-80$ & 277 & $30 \%$ & $50 \%$ & $85 \%$ \\
\hline & Yellow Croaker CEACAM 5 (KKF27703) & $4 e-75$ & 918 & $32 \%$ & $53 \%$ & $98 \%$ \\
\hline & Pike CEACAM 5 (XP_012994902) & $4 e-69$ & 570 & $32 \%$ & $48 \%$ & $86 \%$ \\
\hline & Cichlid Hemicentin-1-like (XP_004550953) & $1 e-65$ & 892 & $30 \%$ & $47 \%$ & $83 \%$ \\
\hline & Salmon Hemicentin-1-like (XP_014056825) & $3 e-65$ & 1041 & $30 \%$ & $46 \%$ & $86 \%$ \\
\hline
\end{tabular}

(A) The human receptor amino acid sequences listed in the left column were used as queries to search the non-redundant protein sequence database for teleost fishes (taxid:32443) by blastp at http:/ /blast.ncbi.nlm.nih.gov/Blast; (B) Human receptor sequences marked with an * indicate those that did not retrieve matches by blastp searches using catfishes (taxid:7995); see Table 1; (C) All searches we performed using the predicted extracellular regions of the receptor sequences (i.e., predicted TM segments and CYT regions were excluded from the searches); (D) For each search result the Expect (E) value reported provides the overall significance of the match with lower values closer to zero being considered more significant. The score indicates quality of the alignment with a higher score associated with a better alignment. This value is calculated using a formula that considers alignment of similar or identical residues, as wells as gaps in the alignment; (E) Representative top-matching teleost protein sequences are listed in the second column from the left; (F) Only sequences with scores $>40.0$ are reported. 


\section{Examination of Stimulatory IpLITR-Mediated Responses}

\subsection{Stimulatory Immunoregulatory Receptors}

Stimulatory immunoregulatory receptors typically have short CYT regions and positively charged TM segments that facilitate intramolecular association with immunoreceptor tyrosine-based activation motif (ITAM)-containing adaptors [29]. For example, the Fc receptor ( $F c R$ ) common gamma chain $(\mathrm{FcR} \gamma)$ associates with members of the FcR family and is requisite for their surface expression and signaling capacity [30]. Engagement of FcRs by binding the Fc region of immunoglobulin induces the activation of Src family kinases (SFKs) that phosphorylate tyrosine residues within the ITAMs of the associated FcR $\gamma$ [30]. Phosphorylation of the ITAM is followed by the rapid recruitment and activation of spleen tyrosine kinase (Syk) [31,32], which then triggers several canonical transduction cascades leading to the induction of effector responses such as phagocytosis, degranulation, and cytokine secretion [33-38]. Alternatively, the adaptor protein DAP12 plays a key role in cytotoxicity mediated by natural killer (NK) cells via its association with activating KIRs [39] and other NKRs [40]. As with FcR $\gamma$, formation of KIR-DAP12 complexes is dependent on electrostatic interactions facilitated by the oppositely charged TM segments of the receptor (positively charged) and adaptor (negatively charged) proteins [29]. A full complement of ITAM-containing adaptor molecules have been identified in fish, which includes homologues of FcR $\gamma$ and DAP12 [41]. This suggests that the mode of receptor-mediated immune cell activation in teleosts is likely similar to what occurs in mammals.

\subsection{Stimulatory IpLITRs Demonstrate a Unique Ability to Associate with Intracellular Signaling Adaptors}

The characteristic TM segment of IPLITR 2.6b, a representative stimulatory IpLITR-type, contains a positively charged lysine residue and a short CYT region that lacks canonical tyrosine-based signaling motifs [27]. Therefore, we predicted that this receptor required an adaptor protein to facilitate its cell surface expression and to stimulate kinase-dependent intracellular signaling networks. We tested this directly using HEK 293T cells co-transfected with hemagglutinin (HA)-tagged IpLITR 2.6b, and demonstrated that this receptor co-immunoprecipitated with the ITAM-containing IpFcR $\gamma, \mathrm{IpFcR} \gamma-\mathrm{L}$, and IpCD3 $\zeta$-L signaling adaptors but not with IpDAP12 [42]. In mammals, stimulatory receptor-types that have lysine residues in their TM segments bind DAP12 but not FcR $\gamma$ [29]. A significant increase in the cell surface expression of IpLITR 2.6b in the presence of IpFcR $\gamma$ or IpFcR $\gamma$-L, but not IpCD3 $\zeta$-L, was observed; indicating that association with an appropriate adaptor is required for localization of the active signaling complex within the plasma membrane [42,43]. These studies also demonstrated that IpLITR 2.6b associated with heterodimeric complexes composed of IpFcR $\gamma$-L and IpCD3 $\zeta$-L (but not IpDAP12) [42], which has been previously observed for $\mathrm{FcR} \gamma-\mathrm{CD} 3 \zeta$ heterodimers during the control of FcR-dependent signal transduction in mammals [44]. Mutation of the lysine residue within the TM segment of IPLITR 2.6b to arginine or an uncharged alanine residue had no effect on either surface expression or adaptor recruitment. In addition, the neutralized TM segment of IpLITR 2.6b not only maintained its ability to bind IpFcR $\gamma-\mathrm{L}$ and IpCD3 $\zeta$-L, but also acquired the ability to bind IpDAP12, which significantly augmented the cell surface expression of IpLITR 2.6b [42]. These observations suggest that, contrary to what has been reported for stimulatory immunoregulatory receptor-adaptor associations in mammals [29], a charged TM segment is not a prerequisite for adaptor recruitment to IPLITR 2.6b. However, the identity of the residues within the TM segment does appear to define the specificity of IpLITR-adaptor protein interactions. Alternatively, neutralizing the negatively charged TM region of the signaling adaptor IpFcR $\gamma$-L completely abrogated assembly with IpLITR $2.6 \mathrm{~b}$ and inhibited the surface expression of the IpLITR 2.6b-IpFcR $\gamma$-L complex [42]. These data strongly suggested that the negatively charged TM segment of the channel catfish adaptor molecule was an important requirement for IpLITR-adaptor assembly. Overall, these biochemical studies confirmed that a putative stimulatory IpLITR-type associated with teleost-specific ITAM-containing adaptors and provided interesting new details regarding the specificity of these interactions. Our next objective was 
to examine the functional implications of IpLITR 2.6b-IpFcR $\gamma$-L interactions by testing the ability of this immunoregulatory protein complex to stimulate various innate immune cell activities.

\subsection{Induction of Intracellular Signaling and Immune Cell Activation by a Stimulatory IpLITR-Adaptor Protein Complex}

To directly examine the functional activities of the IpLITR 2.6b-IpFcR $\gamma$-L signaling subunit we generated an $\mathrm{N}$-terminal HA-tagged chimeric receptor construct consisting of the extracellular region of IpLITR 2.6b fused with the TM segment and ITAM-containing CYT region of IpFcR $\gamma$-L [45]. The IpLITR $2.6 \mathrm{~b} / \mathrm{IpFcR} \gamma$-L chimera was then transfected and stably-expressed in the rat basophilic leukemia (RBL-2H3) cell line, where it could then be triggered using anti-HA mAbs. Using this approach, we demonstrated that IpLITR $2.6 \mathrm{~b} / \mathrm{IpFcR} \gamma$-L activated intracellular signaling mediators and that it was a potent stimulator of the RBL-2H3 degranulation response [45]. Mutating the IpLITR $2.6 \mathrm{~b} / \mathrm{IpFcR} \gamma$-L ITAM tyrosine residues to phenylalanine completely blocked functional outputs, reinforcing the ITAM-dependent nature of these cellular responses. Using phospho-specific Abs and Western blotting, we also observed a unique time-course of extracellular signal-regulated kinase (ERK) $1 / 2$ and protein kinase B (Akt) phosphorylation after IpLITR 2.6b/IpFcR $\gamma$-L triggering, which did not occur using the ITAM mutated receptor [45]. Furthermore, pharmacological inhibitors of SFKs, phosphatidylinositol 3-kinases (PI3Ks), mitogen activated protein kinase (MAPK) kinase (MEK1 and MEK2), and protein kinase Cs (PKC) significantly inhibited IpLITR 2.6b/IpFcR $\gamma$-L-induced degranulation [45]. In comparison, selective inhibitors of the c-Jun N-terminal kinases (JNKs) and p38 MAPK pathways had no effect on stimulated IpLITR 2.6b/IpFcR $\gamma$-L cellular responses. Overall, these studies provided the first functional information for a putative stimulatory IpLITR-adaptor complex and suggested that the ITAM-dependent signaling activated by IpLITR $2.6 \mathrm{~b} / \mathrm{IpFcR} \gamma$-L occurs through classical kinase-dependent intracellular cascades [45]. A proposed ITAM-dependent signaling mechanism utilized by IpLITR 2.6b was summarized previously in [45].

The functional capacity of IpLITR 2.6b/IpFcR $\gamma$-L was further examined using a MAPK signaling array as well as cytokine secretion profiling. Anti-HA crosslinking of IpLITR 2.6b/IpFcR $\gamma$-L increased phosphorylation of several intracellular signaling molecules, including ERK1 $/ 2$, GSK-3 $\alpha / \beta$, GSK-3 $\beta$, RSK1, CREB, JNK (pan), MEK6, MSK2, p388, and Akt2 [46]. This provided a broader view of the intracellular signaling components phosphorylated downstream of IpLITR 2.6b/IpFcR $\gamma$-L triggering. These studies also demonstrated that cells activated via IpLITR 2.6b/IpFcR $\gamma$-L secreted interleukin (IL)-3, IL-4, IL-6, and tumor necrosis factor- $\alpha$ (TNF- $\alpha$ ) at levels comparable to what we observed following activation of the cells with phorbol myristate acetate, calcium $\left(\mathrm{Ca}^{2+}\right)$ ionophore, or stimulation via triggering the endogenous FceRI [46]. This suggested that IpLITR 2.6b/IpFcR $\gamma$-L-mediated signaling events coordinately induce both cellular degranulation and cytokine secretion over a comparable temporal scale. Moreover, when the IpLITR 2.6b/IpFcR $\gamma$-L chimeric construct was triggered with anti-HA mAb opsonized beads, we observed a potent phagocytic response that was dependent on extracellular $\mathrm{Ca}^{2+}$ availability and actin polymerization [46]; thus adding another functional dimension to IpLITR 2.6b/IpFcR $\gamma$-L activation.

In mammals, phagocytic receptors such as FcRs also associate with the ITAM-containing adaptor FcR $\gamma$-chain $[34,47,48]$. Phosphorylation of FcR $\gamma$-chain ITAMs by SFKs leading to the recruitment of Syk, which then serves as the main effector of FcR-mediated phagocytic signaling by directly binding to and/or phosphorylating specific downstream intracellular components [49,50]. Classically, the mediators recruited to FcR-FcR $\gamma$ complexes include isoforms of PI3Ks, Vav, and Rho family GTPases [51-54]; in particular, Rac1 and Cdc42 dynamically control actin polymerization and are required for phagocytic cup formation as well as pseudopod extension [55,56]. Selective pharmacological inhibitors of these mediators were profiled in phagocytic assays in order to obtain detailed information regarding the biochemical pathways that facilitate IpLITR 2.6b/IpFcR $\gamma$-mediated phagocytosis and to compare these mechanisms with the classical mammalian FcR phagocytic mode [57]. Phagocytic activity was measured using a flow cytometric-based assay and $4.5 \mu \mathrm{m}$ fluorescent polystyrene microsphere targets. 
IpLITR 2.6b/IpFcR $\gamma$-L-mediated phagocytosis relied on a similar subset of intracellular effectors for target engulfment and was comparable to the ITAM- and SFK-dependent mode of phagocytosis utilized by mammalian FcRs [49-51]. Specifically, the IpLITR 2.6b/IpFcR $\gamma$-L phagocytic response was inhibited using small molecule inhibitors that targeted SFKs, Syk, PI3Ks, Cdc42, Rac1/2/3, phosphoinositide-dependent kinase 1 (PDK1), Akt, PKC, MEK1/2, and F-actin polymerization [57]. These data provide further biochemical details describing the phagocytic pathway engaged by a teleost immunoregulatory receptor. The marked similarities observed between IpLITR- and mammalian FcR-mediated phagocytosis indicates that ITAM-dependent stimulatory signaling in vertebrates may represent a common, and perhaps evolutionarily conserved, signaling mode for active target engulfment.

\section{Examination of Inhibitory IpLITR-Mediated Responses}

\subsection{Inhibitory Immunoregulatory Receptors}

Inhibitory immunoregulatory receptors establish the activation threshold of immune cells and attenuate stimulatory immunoregulatory receptor-induced effector functions. Inhibitory actions are primarily dependent on immunoreceptor tyrosine-based inhibition motifs (ITIMs) within the CYT regions of putative inhibitory receptors [58-60]. Following receptor triggering, phosphorylation of the tyrosine residue embedded within ITIMs (S/I/V/LxYxxI/V/L) promotes binding of SH2 domain-containing cytoplasmic phosphatases (SHP-1, SHP-2, and SH2-domain containing inositol 5-phosphatase 1 or 2; SHIP1/2). Activated phosphatases dephosphorylate important proximal signaling proteins and transduction molecules in order to block the transmission of kinase-mediated signaling events and inhibit immune cell effector functions such as phagocytosis, degranulation, and NK cell-mediated killing responses [60-62]. Some inhibitory receptors also contain immunoreceptor tyrosine-based switch motifs (ITSMs; [63]) in the CYT region that can similarly inhibit cellular activation via phosphatase recruitment, but ITSMs can also alter cellular signaling via phosphatase-independent mechanisms following the selective recruitment of adaptor proteins such as $\mathrm{SH} 2$ domain protein 1A (SH2D1A) and Ewing's sarcoma (EWS)-activated transcript 2 (EAT-2) [63]. Not surprisingly, many of the identified IpLITRs contain ITIMs and/or ITSMs, and we have investigated the biochemical and functional properties of putative inhibitory IpLITRs, which will be reviewed in this section.

\subsection{Inhibitory IpLITRs Contain ITIMs and Recruit Protein Tyrosine Phosphatases}

We first examined if ITIM-containing IpLITR-types recruited SHP-1 and/or SHP-2 after receptor engagement and phosphorylation of their CYT tyrosines. To do this, expression constructs were generated by fusing the extracellular domain and TM segments of the human NK cell receptor KIR2DL3 to the tyrosine-containing CYT regions of two selected putative inhibitory IpLITR-types, IpLITR 1.2a and IpLITR 1.1b [64]. The extracellular region of KIR2DL3 was used in the fusion constructs since the biological ligand for this receptor is known and readily available (i.e., HLA-Cw3) [60]. The $\mathrm{KIR}_{\mathrm{ED}}$-LITR $\mathrm{CYT}_{\mathrm{T}}$ constructs were originally examined using transient expression experiments in HEK 293T cells [64]. Here we demonstrated that following tyrosine phosphorylation, the CYT regions of IPLITR 1.2a and IPLITR 1.1b recruited SHP-1 and SHP-2 in an ITIM-dependent manner. IpLITR $1.1 \mathrm{~b}$ also had a unique tyrosine-containing TM proximal region lacking classic inhibitory or stimulatory tyrosine-based signaling motifs that, in our studies, did not bind SHP-1 or SHP-2 [64]. After transfection and stable expression of these $\mathrm{KIR}_{\mathrm{ED}}-\mathrm{LITR}_{\mathrm{CYT}}$ constructs in mammalian NK-like cells, we anticipated that HLA-Cw3-positive target cells would effectively engage the chimeric proteins; allowing us to directly examine IpLITR-mediated inhibitory signaling. This is important since, as outlined above, the natural ligands for IpLITRs are unknown. Using this novel system, we demonstrated that IpLITR-mediated signaling events could influence cytotoxic responses and, as predicted, that IpLITR engagement could abrogate NK cell-mediated killing responses [65]. Unexpectedly, we also demonstrated that this inhibitory signaling occurred via both SHP-dependent and -independent mechanisms. 
3.3. Inhibitory IpLITRs Abrogate the NK Cell Killing Response via Both SHP-1-Dependent and-Independent Signaling Pathways

The inhibitory functions of IpLITRs were examined using a vaccinia virus system to express $\mathrm{KIR}_{\mathrm{ED}}$-LITR 1.2a $\mathrm{a}_{\mathrm{CYT}}$ and $\mathrm{KIR}_{\mathrm{ED}}$-LITR $1.1 \mathrm{~b}_{\mathrm{CYT}}$ in mouse spleen-derived cytotoxic lymphocytes [65]. Unlike our previous studies, this allowed us to determine the specific effects of IpLITR-induced signaling on lymphocyte cytotoxicity using B cell targets expressing HLA-Cw3 (e.g., 721.221 cells). The main objectives of this study were to examine the inhibitory signaling pathways activated by IpLITR 1.2a and IpLITR $1.1 \mathrm{~b}$ as well as to determine if the unique proximal region of the IpLITR 1.1b CYT differentially contributed to the regulation of NK cell-mediated cytotoxicity. We observed that the CYT regions of IPLITR 1.2a and IpLITR 1.1b both contributed to the inhibition of lymphocyte-mediated target cell killing and determined that for IpLITR 1.2a, this was a SHP-dependent mechanism [65]. However, the inhibitory function mediated by the CYT region of IpLITR $1.1 \mathrm{~b}$ was not affected by co-expression with a catalytically inactive SHP-1 recombinant protein, suggesting that although IpLITR 1.1b binds SHP-1, its inhibitory activity is not dependent on the catalytic activity of this phosphatase [65].

The IpLITR 1.1b CYT region contains six tyrosine residues, evenly distributed between its membrane proximal $\left(Y^{433}, Y^{453}\right.$, and $\left.Y^{463}\right)$ and distal $\left(Y^{477}, Y^{499}\right.$, and $\left.Y^{503}\right)$ regions [64]. The distal region contains two ITIMs located at $\mathrm{Y}^{477}$ and $\mathrm{Y}^{499}$ and one overlapping ITSM $\left(\mathrm{Y}^{503}\right)$ and when tested as a separate

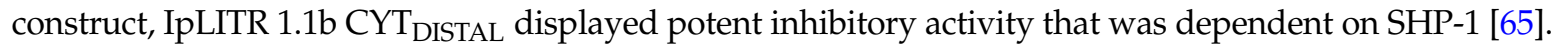
We also generated a construct encoding only the CYT proximal region of IpLITR 1.1b and, surprisingly, this receptor variant also blocked NK cell-mediated killing responses despite the fact this construct did not contain any ITIMs or ITSMs and could not recruit SHP-1 or SHP-2 [64,65]. This revealed that the SHP-independent inhibitory pathway being activated by IPLITR $1.1 \mathrm{~b}$ was likely facilitated by one of the tyrosine residues present within its unique proximal CYT region. We then determined that the peptide

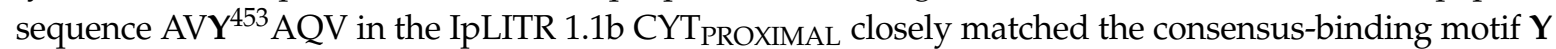
$[T / A / S][K / R / Q / N][M / I / V / R]$, which is required for recruiting the C-terminal Src kinase (Csk) [66].

In mammals, Csk has been identified as a major endogenous inhibitor of SFK-mediated cellular activities $[67,68]$ and, in general, is an important regulator of intracellular signaling events. However, the ability of Csk to negatively influence cellular immune responses has only recently been recognized $[69,70]$. The inhibitory actions of Csk are dependent on its ability to phosphorylate a conserved tyrosine residue located at the C-terminus of SFKs (i.e., Lyn, Fyn, Hck, etc.), which inhibits SFK catalytic activities $[67,68]$. Kinase-mediated inhibitory signaling opposes the classical phosphatase-driven attenuation of immune cell responses, but is likely equally important in terms of the overall regulation of immunity. Using co-immunoprecipitation and site-directed mutagenesis, we confirmed that $\mathrm{Y}^{453}$ was indeed required for Csk binding to the IPLITR 1.1b proximal CYT region as well as the inhibitory activity of IpLITR 1.1b [65]. Recruitment of Csk to the proximal CYT region of IpLITR $1.1 \mathrm{~b}$ would appropriately localize this kinase for targeted phosphorylation of SFKs rendering them inactive and thus abrogating the early signaling events required for cellular activation, such as NK cell-mediated killing. These results were the first functional studies reported for an inhibitory ITIM-containing IpLITR and the first to suggest the involvement of Csk as a novel inhibitory signaling mechanism used by a teleost immunoregulatory receptor [65]. Furthermore, the unique proximal and distal inhibitory signaling mechanisms mediated by the IpLITR 1.1b CYT reveal marked versatility in the signaling properties within a single LITR. In the subsequent sections, we will review aspects of IpLITR functional plasticity in more detail.

\section{Examination of IpLITR-Mediated Functional Plasticity}

\subsection{Functional Plasticity and Immunoregulatory Receptors}

The classification of immunoregulatory receptors as inhibitory or stimulatory has depended primarily on whether or not they contain key signaling motifs within the CYT region such as ITIMs (inhibitory receptors) or ITAMs (stimulatory receptors). However, the functional outcome of 
immunoregulatory receptor engagement does not always coincide with the presence of these canonical motifs, as alternative mechanisms of ITIM- or ITAM-dependent signaling events may contribute to functional versatility. For example, there are several reports demonstrating that ITIM-encoding receptors can also stimulate immune cell responses through a wide variety of functionally distinct signaling mechanisms [71-76]. In addition, inhibitory actions triggered by phosphorylated ITAMs have also been described [77-81]. Functional plasticity in the transduction events controlled by modular protein domains likely serves as an important regulatory mechanism for the fine control of innate immune cell effector functions. Integrated receptor-mediated regulation of signal transduction is also likely to be dependent on many additional factors including the immune cell-type(s) involved as well as the available repertoire of intracellular adaptor and effector molecules. The magnitude and duration of immunoregulatory receptor activation by natural ligands may also play a key role in the type of functional outcomes that occur following receptor engagement. We have already demonstrated that IpLITR 1.1b inhibits NK cell-mediated killing using a classical ITIM- and SHP-dependent mechanism that was regulated by its distal CYT region [65]. Interestingly, this receptor also abrogated NK cell responses using an ITIM-independent mechanism that relied on the recruitment of Csk to a tyrosine residue located in the proximal CYT region [65]. Although the signaling versatility observed contributed to the same functional outcome, it occurred through two distinct intracellular mechanisms. Moreover, we recently demonstrated that IpLITR $1.1 \mathrm{~b}$ could potently activate a phagocytic response in RBL-2H3 cells (a representative myeloid cell type), suggesting that the differential recruitment of signaling mediators in specific immune cell types (i.e., lymphoid $v s$. myeloid) may facilitate a context-dependent plasticity during the receptor-mediated control of cellular processes [46]. Our findings using IpLITRs agree with observations from mammalian models describing alternative mechanisms of immunoregulatory receptor-mediated signaling that extend beyond their putative classifications as strictly inhibitory or stimulatory receptor-types. Overall, alternative stimulatory signaling downstream of IpLITR $1.1 \mathrm{~b}$ activation provides the basis for the examination of IpLITR functional plasticity as an important immunomodulatory mechanism controlled by these teleost receptors.

\subsection{Induction of Phagocytosis and Stimulatory Signaling by an Inhibitory IpLITR}

In the original description of IpLITR 1.1b functional plasticity, we demonstrated that this receptor stimulated phagocytosis and induced phosphorylation of important signal transduction targets, including ERK1/2 and Akt [46]. However, unlike IpLITR 2.6b/IpFcR $\gamma$-L, IpLITR 1.1b did not induce the secretion of cytokines and the kinetics of IPLITR 1.1b-induced phosphorylation of ERK1/2 and Akt was significantly different from the ITAM-mediated responses. IpLITR 1.1b stimulatory activities were also independent of any association with an ITAM-containing adaptor protein, and phagocytic activity stimulated by IpLITR 1.1b was insensitive to treatment with the extracellular $\mathrm{Ca}^{2+}$ chelator EDTA, which further distinguished IpLITR 1.1b-mediated signaling from the IpLITR 2.6b/IpFcR $\gamma$-L pathway [46]. Finally, without the CYT region, IpLITR $1.1 \mathrm{~b}$ was still expressed on the cell surface but it no longer stimulated a phagocytic response; indicating that the signal to initiate phagocytosis was due to events promoted by residues contained within the CYT [46]. To further understand the requirements for IpLITR 1.1b-mediated phagocytosis, we again considered the unique proximal and distal composition of tyrosine residues within the CYT in an attempt to derive a mechanism that could be examined in detail using biochemical and functional assays. The first step in this process was to use bioinformatics to predict what intracellular molecules might bind to the IpLITR 1.1b CYT and to hypothesize how these transduction elements would participate in the activation of machinery required for actin polymerization as well as plasma membrane remodeling during target engulfment. Since IpLITR $1.1 \mathrm{~b}$ does not contain a classical ITAM, or any other recognizable stimulatory motifs that are known to facilitate phagocytosis [64], an alternative mode for the intracellular stimulation of IpLITR 1.1b-mediated phagocytosis was considered. Based on the results described in [46], this mechanism will be explained further below.

One potential mechanism derived from mammalian models hypothesizes that the ITSM-containing distal region of the CYT is primarily responsible for IpLITR $1.1 \mathrm{~b}$ functional plasticity. For example, 
ITSMs can bind SHPs that commonly mediate phosphatase-dependent cellular inhibition [82]. However, as their name suggests, this motif can also alter conformation to selectively recruit stimulatory adaptor proteins including SH2D1A and EAT-2 that typically activate, rather than inhibit, effector functions in immune cells [83]. In particular, ITSMs can facilitate stimulatory signaling through SH2D1A-dependent recruitment and activation of the p85 subunit of class IA PI3Ks [84,85], which can then induce Akt phosphorylation downstream of phosphatidylinositol 3,4,5-trisphosphate $\left(\mathrm{PI}(3,4,5) \mathrm{P}_{3}\right)$ production as well as directly modulate phagocytosis [63]. ITIM- and ITSM-mediated induction of cellular activation has also been shown to involve SHP-2 [86], which instead of abrogating downstream signaling, can serve as a key scaffold for proteins involved in cellular responses. In this scenario, SHP-2 recruitment to ITIMs and/or ITSMs results in phosphorylation at a C-terminal tyrosine that then serves as a binding site for the SH2-containing adaptor molecule growth factor receptor-bound 2 (Grb2) [87,88]. Grb2 associates with members of the Dab/Dos family of scaffolding proteins, known as the Grb2-associated binders (Gabs). When phosphorylated, Gab2 has been shown to bind and activate class IA PI3Ks, again resulting in the recruitment and phosphorylation of downstream targets that include PDK1 and Akt as well as other components of the phagocytic machinery [89-92]. During IpLITR 1.1b-mediated phagocytosis, we predict that Grb2 recruitment to the activated receptor may rely on SHP-2 binding to the ITIMs $\left(\mathrm{Y}^{477}\right.$ and /or $\left.\mathrm{Y}^{499}\right)$, and/or the ITSM $\left(\mathrm{Y}^{503}\right)$. SHP-2 recruitment would allow for the association of larger protein heteromers, including potential interactions with Gab2 and formation of the SHP-2-Grb2-Gab2 ternary signaling complex that would allow for the subsequent activation of class I PI3Ks [88,93-95]. The involvement of SHP-2 as an intracellular scaffold capable of engaging $\mathrm{PI}(3,4,5) \mathrm{P}_{3}$-dependent cellular activation pathways provides an explanation for context-dependent functional outcomes contrasting our previously reported SHP-dependent inhibition of NK cell killing induced by IpLITR 1.1b [65]. An overall summary schematic of this proposed signaling mechanism is provided in Figure 1.

The stimulatory actions of IPLITR $1.1 \mathrm{~b}$ are unlikely limited to only the distal CYT region containing the ITIMs and ITSM. As also outlined in Figure 1, $\mathrm{Y}^{463}$ matches the known Grb2-binding motif ( $\mathrm{YxN}$ ) that would facilitate direct Grb2 binding to the CYT proximal region of IpLITR 1.1b [66]. As already mentioned, Grb2 is an important intracellular scaffold that is also known to associate with guanine nucleotide exchange factors (GEF), such as Son of Sevenless (SoS), which interacts with the SH3 domain of Grb2 via a polyproline-rich sequence [96]. Formation of the Grb2-SoS signaling complex also commonly involves targeting the GEF activity of SoS to the membrane-associated Ras superfamily of small GTPases, subsequently leading to the activation of the Raf-MEK-ERK signaling cassette [97,98]. Therefore, direct or indirect (via SHP-2) recruitment of Grb2 to the proximal and/or distal CYT regions of IPLITR 1.1b, respectively, may provide explanations for how this receptor can induce the downstream activation of both ERK1/2 and Akt signaling in RBL-2H3 cells. Alternatively, Grb2 binding directly to phosphorylated $\mathrm{Y}^{463}$ (i.e., YxN motif) during phagocytosis could also recruit Gab2 and the class I PI3Ks. Gab2-dependent recruitment and activation of class IA PI3K heterodimers (p85-p110) would increase the local generation of $\mathrm{PI}(3,4,5) \mathrm{P}_{3}$, which is required for actin-dependent extension of pseudopods and the engulfment of large extracellular particles [91,95,99,100]. IpLITR 1.1b-induced production of $\mathrm{PI}(3,4,5) \mathrm{P}_{3}$ could also attract additional pleckstrin homology $(\mathrm{PH})$ domain-containing adaptors like Vav, another important GEF, that directly bind to plasma membrane $\mathrm{PI}(3,4,5) \mathrm{P}_{3}[101]$. Vav activation stimulates Rho family GTPases including Cdc42, Rac1, and RhoA that control local actin polymerization during the formation of lamellipodia required for phagocytosis [54]. Control of Rho family GTPase activity by Vav has also been shown to play an important role in FcR $\gamma-$, complement receptor-, and CEACAM-mediated phagocytosis [101,102]. It still remains to be seen if Vav-dependent regulation of Rho family GTPases participates in IpLITR-mediated phagocytosis, however, interactions between IPLITR 1.1b and many of the molecules implicated above are the focus of ongoing investigations in our lab. 


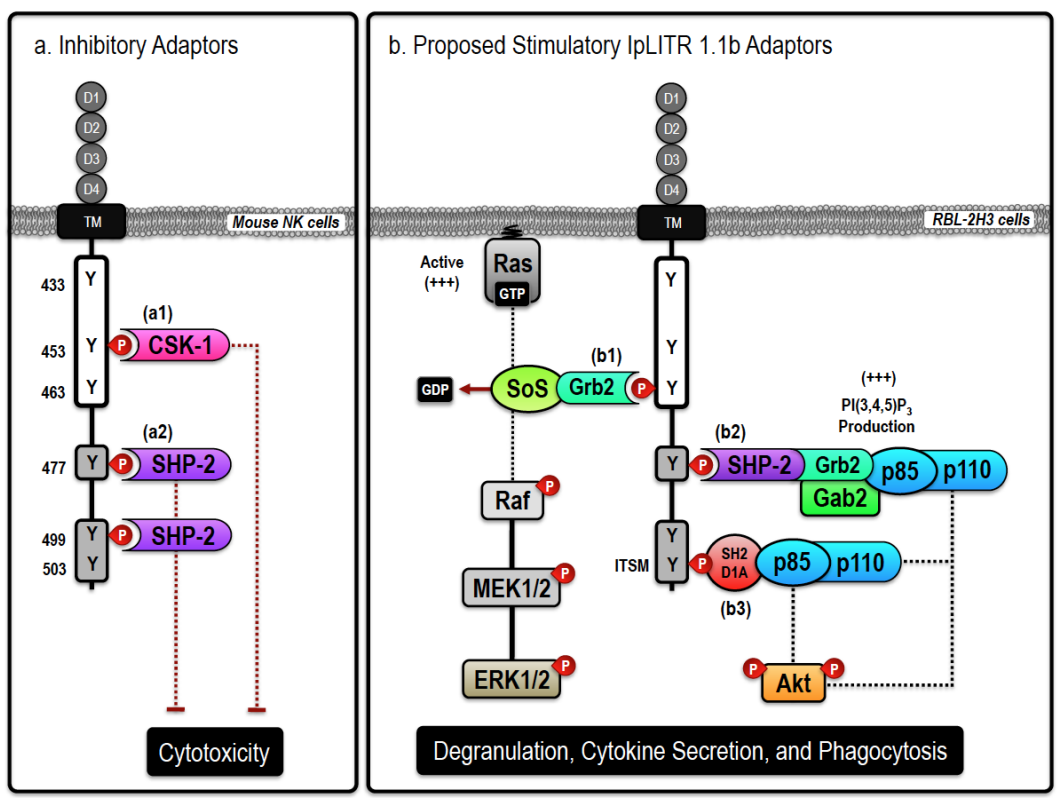

Figure 1. Proposed inhibitory and stimulatory (Ictalurus punctatus) leukocyte immune-type receptors (IpLITR) 1.1b-mediated intracellular signaling events. Schematic representation of the proposed inhibitory (a) and stimulatory (b) signaling events mediated by IpLITR 1.1b in transfected cells. The cytoplasmic tail (CYT) region of IpLITR 1.1b contains six tyrosine residues $\left(\mathrm{Y}^{433}, \mathrm{Y}^{453}, \mathrm{Y}^{463}, \mathrm{Y}^{477}, \mathrm{Y}^{499}\right.$, and $\mathrm{Y}^{503}$ ) that, when phosphorylated, serve as potential docking sites for various intracellular signaling adaptors. (a) In mouse natural killer (NK) cells, we demonstrated that engagement of IpLITR 1.1b caused a potent inhibition of NK cell-mediated cytotoxicity due to the recruitment of Csk-1 at $\mathrm{Y}^{453}$ (a1) or the binding of SH2 domain-containing cytoplasmic phosphatases (SHP) at $\mathrm{Y}^{477}$ and/or $\mathrm{Y}^{499}$, which are in immunoreceptor tyrosine-based inhibition motifs (ITIMs) (a2) [64,65]. The immunoreceptor tyrosine-based switch motifs (ITSM) located at $\mathrm{Y}^{503}$ may also recruit SHP phosphatases but this has not been examined. (b) IpLITR 1.1b engagement also induced phosphorylation of ERK1/2 and Akt as well as promoted phagocytosis in transfected rat basophilic leukemia (RBL)-2H3 cells [46]. These stimulatory effector cell functions could be mediated by the following mechanisms; (b1) direct recruitment of growth factor receptor-bound $2(\mathrm{Grb} 2)$ to the $\mathrm{YxN}$ motif at $\mathrm{Y}^{463}$ may mediate the recruitment, and associated GEF activity, of SoS or the Gab2/class I PI3K (p85/p110) signaling complex. SoS is known to stimulate the accumulation of GTP-loaded Ras that would facilitate the stepwise phosphorylation of the Raf-MEK-ERK cassette. Alternatively, the Gab2 adaptor can localize class I PI3K activation to allow for targeted accumulation of the important signal transduction molecule phosphatidylinositol 3,4,5-trisphosphate $\left(\mathrm{PI}(3,4,5) \mathrm{P}_{3}\right)$; (b2) ITIM-mediated recruitment of SHP-2 at $\mathrm{Y}^{477}$ or $\mathrm{Y}^{499}$, could recruit Grb2 and Gab2 allowing for the association of holomeric class I PI3Ks (p85/p110) leading to Akt phosphorylation and induction of phagocytosis. SHP-2-dependent recruitment of class I PI3Ks could also occur at the C-terminal ITSM located at $\mathrm{Y}^{503}$. SHP-2-dependent Grb2 recruitment may also trigger the SoS/Ras/Raf/MEK-dependent activation of ERK1/2; (b3) SH2D1A-mediated binding of PI3K (p85/p110) to the ITSM at $\mathrm{Y}^{503}$ is also possible. In general, class I PI3K activation can result in Akt phosphorylation or the recruitment of other $\mathrm{PI}(3,4,5) \mathrm{P}_{3}$-dependent signaling proteins, including Vav, that are known to regulate phagocytosis. In addition, ITSM-mediated signaling can also recruit the adaptor EAT-2, closely related to SH2D1A, which is not shown here. For clarity, the role of signaling events dependent upon extracellular $\mathrm{Ca}^{2+}$ entry or intracellular $\mathrm{Ca}^{2+}$ mobilization have also been excluded.

In addition to Csk, SHP-1, and SHP-2 reported in [65], we have biochemical evidence for the binding of Grb2, SH2D1A, and the class IA PI3K regulatory subunit p85 to the CYT region of IpLITR 1.1b (unpublished observations; Zwozdesky and Stafford). Overall, our studies using IpLITR 1.1b are the first to demonstrate functional plasticity for an ITIM-containing teleost immunoregulatory receptor. 
At present, the precise mechanisms of IpLITR 1.1b-induced phagocytosis are unknown, but the events leading to this outcome are clearly distinct from those facilitated by the prototypical ITAM-dependent pathway used by IpLITR 2.6b and may ultimately represent a novel cellular mode of actin-dependent target engulfment.

\subsection{IpLITRs Activate Distinct Phagocytic Modes: Further Insights into IpLITR 1.1b-Mediated Functional Plasticity}

Details of an alternative ITAM-independent IpLITR-induced phagocytic pathway were revealed in [57]. These studies indicated that despite convergence on the control of actin polymerization dynamics, IpLITR $1.1 \mathrm{~b}$ clearly operates independently of several of the key components of the ITAM-dependent signaling machinery. IpLITR 1.1b-expressing cells also displayed a unique target acquisition and engulfment phenotype that was not observed during IpLITR 2.6b/IpFcR $\gamma$-induced phagocytosis. Phagocyte phenotypes were examined by confocal microscopy, which demonstrated that IpLITR $1.1 \mathrm{~b}$-expressing cells often formed extended membranous protrusions that captured their targets in phagocytic cup-like structures but failed to completely internalize them. Incomplete target engulfment is indicative of a stalled phagocytic phenotype that was often observed during IpLITR 1.1b-mediated phagocytosis ( $44 \%$ of cells examined), but was rarely observed for the IpLITR $2.6 \mathrm{~b} / \mathrm{IpFcR} \gamma$-L-expressing cells ( $\sim 3 \%$ of cells) that readily internalized extracellular targets (i.e., $\sim 60 \%$ of the cells analyzed had completely engulfed two or more beads) [57]. Although the capture and partial engulfment phenotype was common during IPLITR 1.1b-mediated phagocytosis, $\sim 30 \%$ of the analyzed cells internalized at least one $4.5 \mu \mathrm{m}$ bead. Surprisingly, while incubations at $22^{\circ} \mathrm{C}$ inhibited IpLITR $2.6 \mathrm{~b} / \mathrm{IpFcR} \gamma$-L, this lower temperature had no effect on the ability of IpLITR 1.1b-expressing cells to capture and partially engulf beads; although the depressed temperature did reduce the ability of IpLITR 1.1b-expressing cells to completely engulf extracellular targets (i.e., from $30 \%$ to $10 \%$ internalization). Moreover, while small molecule inhibitors of major kinase and GTPase signaling systems had significant inhibitory effects on the IPLITR 2.6b/IpFcR $\gamma$-L-mediated phagocytic pathway (described above), IpLITR 1.1b-induced phagocytosis was insensitive to the majority of these pharmacological inhibitors. For example, IpLITR $1.1 \mathrm{~b}$ phagocytosis was only significantly blocked by treatment with inhibitors of SFKs, Syk, and F-actin nucleation, whereas inhibition of PDK1, Cdc42, Rac, PI3Ks, and PKCs were ineffective [57]. Based on these findings, we propose a distinctive cellular model of phagocytosis for IpLITR $1.1 \mathrm{~b}$ that requires a minimal set of intracellular signaling components that directly associate with the actin polymerization machinery (Figure 2). We also hypothesize that the proximal and distal regions of the IPLITR 1.1b CYT may differentially participate in the recruitment and activation of phagocytic effectors. For IpLITR 1.1b to activate phagocytosis, our recent results [57] suggest that it must stimulate actin polymerization and may require the catalytic activity of the SFK and Syk families of intracellular kinases. Therefore, we propose that CYT proximal region recruits the actin polymerization machinery into the vicinity of a Syk-dependent activation cassette within the distal region of the CYT, which is then triggered following IpLITR $1.1 \mathrm{~b}$ engagement by extracellular targets (Figure 2). In co-immunoprecipitation studies we have also recently observed that following tyrosine phosphorylation, IpLITR $1.1 \mathrm{~b}$ associates with the non-catalytic region of tyrosine kinase adaptor protein 1 (Nck) [103], WASp family verprolin-homologous protein-2 (WAVE2) [104], and Syk (unpublished observations; Zwozdesky and Stafford). These novel data add to the growing repertoire of molecules that bind to IPLITR $1.1 \mathrm{~b}$ and, importantly, link the CYT region of IpLITR $1.1 \mathrm{~b}$ to endogenously available intracellular proteins that regulate actin-dependent phagocytosis. 


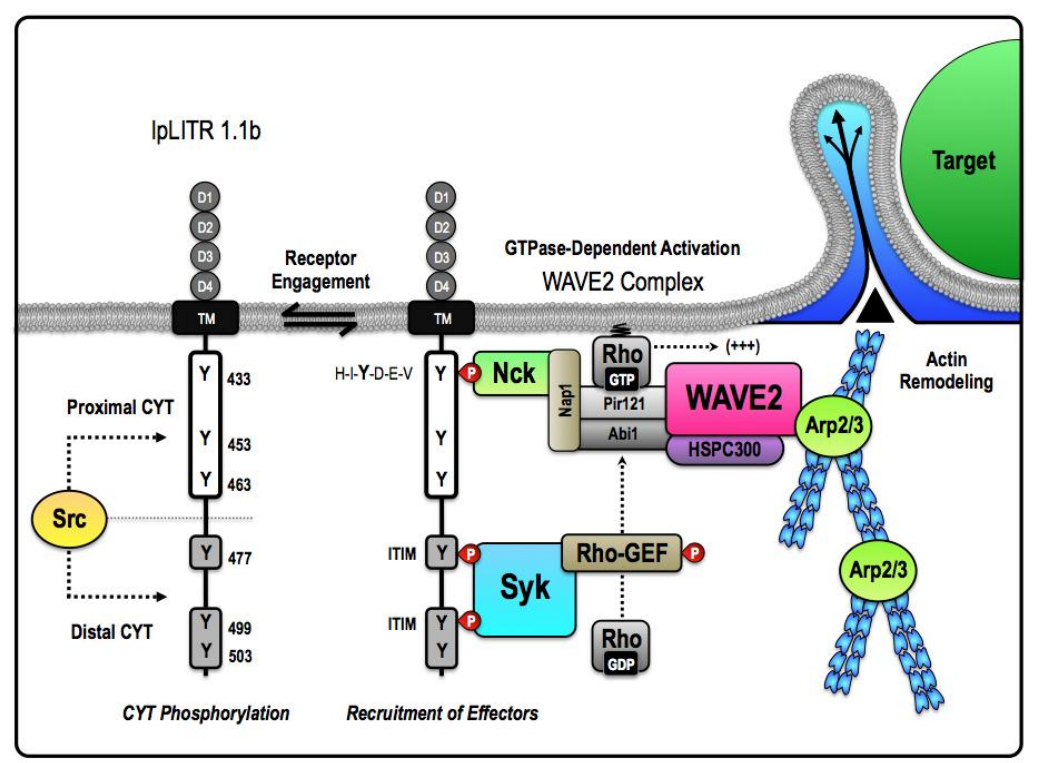

Figure 2. Proposed mechanism for an ITAM-independent target acquisition and engulfment pathway facilitated by pLITR 1.1b. The unique short-circuited version of phagocytosis exhibited by IpLITR 1.1b-expressing cells likely requires that the proximal and distal regions of the IPLITR 1.1b CYT differentially participate in the recruitment and activation of select phagocytic effectors. Our results suggest that IpLITR 1.1b-mediated regulation of the actin polymerization machinery is dependent upon the catalytic activity of the Src and spleen tyrosine kinase (Syk) families of intracellular kinases [57]. We hypothesize that Src serves to place IpLITR 1.1b in a primed state that facilitates basal or constitutive coupling of IpLITR 1.1b to the minimal intracellular machinery required for target acquisition and phagocytic cup extension. In this model, the cytosolic adaptor non-catalytic region of tyrosine kinase adaptor protein 1 (Nck) is recruited to the consensus interaction motif H-I-Y-D-E-V located at $Y^{433}$ in the proximal CYT region of IpLITR 1.1b. Nck has been shown to associate with the WAVE2 complex; a highly conserved pentameric heterocomplex that dynamically regulates Arp2/3-dependent actin polymerization [104]. Importantly, in mammalian cells, WAVE2 is expressed ubiquitously and found as a complex with four other proteins: Pir121, Nap1, Abi-1, and HSPC300 [104]. The mature WAVE2 complex is basally inactive and directly interacts with the SH3 domain of Nck through Nap1 $[103,105]$. Activation of the WAVE2 complex requires state-specific phosphorylation as well as interactions with GTP-bound Rho superfamily proteins, most commonly Rac [106]. As a result, we propose that the assembly of the Nck-WAVE2 complex within the proximal CYT region of IpLITR 1.1b could be coupled to recruitment of a stimulatory Rho-GEF within the distal CYT region. In particular, the spacing of the tyrosines in IpLITR 1.1b suggest that Syk could be recruited to two tandem ITIM motifs at $Y^{477}$ and $\mathrm{Y}^{499}$ in the distal CYT region. Based on comparisons with other phagocytic receptors, we suspect that activation of the cytosolic Rho-GEF could be Syk-dependent. Syk activation of the Rho-GEF would provide the necessary catalyst for rapid actin-driven membrane protrusions via the WAVE2 complex. Together, this mechanism would encompass the minimal machinery required for PI3K-independent target capture pathway by IpLITR $1.1 b$.

Receptor-specific recruitment of Nck, WAVE2, and Syk to IpLITR 1.1b helps to clarify how actin-driven membrane remodeling may be controlled by a putative inhibitory receptor. For example, as described for the human phagocytic receptor CEACAM3 [103], WAVE2 may indirectly associate with IpLITR 1.1b using the adaptor Nck that, based on detailed Src homology 2 (SH2)-domain binding studies [105], could interact with the consensus sequence H-I-Y-D-E-V located around $\mathrm{Y}^{433}$ in the proximal region of the IpLITR 1.1b CYT [64]. Following or during the recruitment of intracellular effectors responsible for the destabilization of the actin cytoskeleton to the proximal CYT region, Syk may bind the distal CYT region of IpLITR $1.1 \mathrm{~b}$ by interacting with phosphorylated tyrosines, $\mathrm{Y}^{477}$ and $\mathrm{Y}^{499}$, that are positioned in two tandem ITIM motifs capable of accommodating both of the $\mathrm{SH} 2$ 
domains of Syk. This atypical mode of Syk recruitment to tandem ITIMs has already been demonstrated for platelet endothelial cell adhesion molecule-1 (PECAM-1) [107]. The tandem ITIMs located within the CYT region of PECAM-1 are spaced such that the tyrosines are separated by twenty-two amino acids. Interestingly, this is also the precise separation between $\mathrm{Y}^{477}$ and $\mathrm{Y}^{499}$ within IpLITR 1.1b and might explain how Syk also interacts with the distal CYT region (Figure 2). Once recruited to IpLITR 1.1b, we predict that Syk would bind and activate an intracellular Rho-GEF (i.e., Vav or RhoA) that could then directly regulate one of the many known Rho GTPases that are responsible for controlling rapid actin-driven membrane protrusions through activation of Arp2/3 and the WAVE2 complex [106]. Based on our current data, the Rho family GTPases involved are unlikely to be either Cdc42 or Rac1/2/3 [57]. Overall, this proposed mechanism provides the framework for exploring a new mode of ITAM-independent phagocytosis and will be investigated further in our lab. It is also worth noting that this revised model for IpLITR 1.1b-mediated phagocytosis does not include the activity of class I PI3Ks, which is in agreement with our pharmacological data. However, as proposed in Figure 1, class I PI3Ks may still participate in other IPLITR 1.1b-dependent functional responses and more work is still required to reconcile the contribution and dynamics of PI3K involvement during IpLITR 1.1b-mediated phagocytosis. In mammals, FcR-stimulated phagocytosis proceeds through distinctive phases that are dependent on the coordinate activities of several key effector molecules [108]. These phases include an early PI3K-independent stimulation of actin polymerization that drives the extension of the phagocytic cup to capture targets, followed by a PI3K-dependent contractile mechanism that subsequently closes phagosomes around targets [108]. The size of the extracellular target directly influences these processes, as the engulfment of larger particles (i.e., $>3 \mu \mathrm{m}$ ) requires accessory signaling events to promote the final stages of target internalization [51,101,109-113]. We hypothesize that IpLITR 1.1b activates the early PI3K-independent phases of the phagocytic process over a broad range of temperatures; however, unlike IpLITR 2.6b/IpFcR $\gamma$-L, IPLITR 1.1b-expressing cells are not able to effectively stimulate class I PI3K catalytic activity and therefore generally exhibit a stalled phagocytic phenotype. Stalled phagocytosis has been observed in other studies using cells treated with broad-spectrum pharmacological inhibitors of PI3Ks, and this effect was only evident using large beads (i.e., $>3 \mu \mathrm{m}$ ) [51,113]. All together, these data provide another possible distinction between ITAM-mediated phagocytosis and the alternative PI3K-independent phagocytic mode utilized by IpLITR $1.1 b$.

\section{Conclusions}

In this review, we have described the ongoing characterization of IpLITRs; a highly polymorphic family of teleost immunoregulatory proteins displaying both structural and phylogenetic relationships with repertoires of immune proteins found throughout mammals. Stimulatory and inhibitory IpLITR-types are co-expressed by a variety of myeloid and lymphoid cell-types in catfish and, as reviewed here, they can also regulate cell-mediated cytotoxicity, cytokine secretion, degranulation, and phagocytosis when expressed in representative mammalian immune cell-lines. Although they clearly display potent immunoregulatory potentials, endogenous ligands for IpLITRs are currently unknown and their overall contributions to cellular immunity in teleosts have not yet been established. As it stands, it is possible that members of the IpLITR family may function as teleost FcR-like proteins, regulators of NK cell responses (i.e., NKRs), and as adhesion proteins or pathogen recognition molecules akin to members of the human CEACAM family. However, establishing these functional relationships will depend on further experiments designed to identify IpLITR ligands and explore the precise in vivo functions of individual receptors using fish immune cells. Although our work to date has relied on heterologous expression of IpLITRs in mammalian cells, this strategy has allowed us to demonstrate important conserved aspects regarding IpLITR-mediated stimulatory and inhibitory immunoregulatory signaling events and revealed some unanticipated aspects regarding IpLITR signaling versatility. In particular, it is now clear that the signaling mechanisms responsible for IpLITR-mediated immune regulation are both cell- and context-specific. The unique activity of 
IpLITRs in different mammalian immune cell systems also reinforces the role of protein interaction domains during the evolution of immunoregulatory receptor-based signaling networks. The inherent modularity of important signaling motifs within the transduction machinery allows for complex and novel regulatory behaviors to arise from relatively simple genetic events such as recombination, deletion, or insertion [114]. As a result, classifications of stimulatory or inhibitory receptors must attempt to match functional outcomes to the presence of canonical immunoregulatory domains such as ITIMs or ITAMs. Alternatively, biochemical studies must be aimed at mapping the relative importance of unique domain organizations within receptor variants in order to better understand receptor-specific contributions to the spatiotemporal activation of transduction molecules within different immune cell types. Studies using these methodologies, including those described here using IpLITRs, already suggest that the heterogeneity observed within the intramolecular interactions between unique immunoregulatory receptors and the diverse complement of intracellular effectors likely facilitates intricate tuning of responses through selective signaling dynamics. The presence of diverse multi-receptor systems throughout immune cell lineages further compound the apparent complexity required for the integrated control of innate immunity. At present, we are only beginning to understand the significance of functional plasticity within individual immunoregulatory receptors, including IpLITRs; however, specific details regarding the intracellular mechanisms responsible for the signaling versatility observed are only now emerging. Herein, we propose simple context-specific models for IPLITR-mediated immune cell regulation that require a minimal complement of intracellular signaling components. Importantly, these suggested signaling mediators and many others that may participate in the phagocytic process are highly conserved among vertebrates and in particular for our studies they are very similar between mammals and fish (Table 1). Therefore, the insights gained from our heterologous studies demonstrate thtat IpLITR-mediated responses in mammalian cells feature the same signaling components that are likely present in fish immune cells (Table 1). Further elucidation of these mechanisms will hopefully reveal insights into how immunoregulatory receptor plasticity has evolved and perhaps continue to uncover novel roles for canonical ITIM- and ITAM-encoding receptors. These foundational studies of IpLITR-mediated signaling events have set the stage for future studies targeted at understanding how the dynamic control of intracellular events controlled by immunoregulatory receptors contribute to the conserved activities of innate immune cells across vertebrates.

Acknowledgments: This work was supported by grants from: the Natural Sciences and Engineering Council of Canada (NSERC; grant\# RGPIN-2012-341209) awarded to James Stafford; graduate teaching assistantships awarded by the Department of Biological Sciences to Chenjie Fei, Dustin Lillico, and Myron Zwozdesky; an NSERC PGS-D, Alberta Innovates Health Solutions Graduate Studentship, Honorary Izaak Walter Killam Memorial Scholarship, and University of Alberta Dissertation Fellowship awarded to Joshua Pemberton; and a Chinese Scholarship Council scholarship to Chenjie Fei.

Author Contributions: Chenjie Fei, Joshua Pemberton, and James Stafford wrote the manuscript. Dustin Lillico and Myron Zwozdesky provided data, and edited the manuscript.

Conflicts of Interest: The authors declare no conflict of interest.

$\begin{array}{ll}\text { Abbreviations } & \\ \text { Abs } & \text { antibodies } \\ \text { Akt } & \text { protein kinase B } \\ \text { CEACAM } & \text { carcinoembryonic antigen-related cell adhesion molecule } \\ \text { Csk } & \text { C-terminal Src kinase } \\ \text { CYT } & \text { cytoplasmic tail } \\ \text { EAT-2 } & \text { Ewing's sarcoma (EWS)-activated transcript } 2 \\ \text { ERK } & \text { extracellular signal-regulated kinase } \\ \text { FCR } & \text { Fc receptor } \\ \text { FCRL } & \text { FcR-like protein } \\ \text { FCRg } & \text { FcR common gamma chain }\end{array}$




$\begin{array}{ll}\text { Gab } & \text { Grb2-associated binder } \\ \text { GEF } & \text { guanine nucleotide exchange factors } \\ \text { Grb2 } & \text { growth factor receptor-bound 2 } \\ \text { HA } & \text { hemagglutinin } \\ \text { IgSF } & \text { immunoglobulin superfamily } \\ \text { ITAM } & \text { immunoreceptor tyrosine-based activation motif } \\ \text { ITIM } & \text { immunoreceptor tyrosine-based inhibition motif } \\ \text { ITSM } & \text { Immunoreceptor tyrosine-based switch motif } \\ \text { IL } & \text { interleukin } \\ \text { JNK } & \text { c-Jun N-terminal kinase } \\ \text { KIR } & \text { killer Ig-like receptor } \\ \text { LILR } & \text { leukocyte Ig-like receptor } \\ \text { LITR } & \text { leukocyte immune-type receptor } \\ \text { LRC } & \text { leukocyte receptor complex } \\ \text { mAb } & \text { monoclonal antibody } \\ \text { ERK } & \text { mitogen activated protein kinase } \\ \text { NITR } & \text { novel immune-type receptor } \\ \text { NK } & \text { natural killer } \\ \text { NKRs } & \text { NK receptors } \\ \text { PH } & \text { pleckstrin homology } \\ \text { PI3K } & \text { phosphatidylinositol 3-kinase } \\ \text { PI(3,4,5)P3 } & \text { phosphatidylinositol 3,4,5-trisphosphate } \\ \text { PTK } & \text { protein tyrosine kinases } \\ \text { PKC } & \text { protein kinase C } \\ \text { RBL } & \text { rat basophilic leukemia } \\ \text { SFK } & \text { Src family kinase } \\ \text { SHP } & \text { SH2 domain-containing cytoplasmic phosphatases } \\ \text { SH2D1A } & \text { SH2 domain protein 1A } \\ \text { SHIP } & \text { SH2-domain containing inositol 5-phosphatase } \\ \text { SoS } & \text { Son of Sevenless } \\ \text { Syk } & \text { spleen tyrosine kinase } \\ \text { TM } & \text { transmembrane } \\ \text { TNF- } \alpha & \text { WAVE2 } \\ \text { WHily verprolin-homologous protein-2 } \\ \end{array}$

\section{References}

1. Barrow, A.D.; Trowsdale, J. The extended leukocyte receptor complex: Diverse ways of modulating immune responses. Immunol. Rev. 2008, 224, 98-123. [CrossRef]

2. Akula, S.; Mohammadamin, S.; Hellman, L. Fc Receptors and their appearance during vertebrate evolution. PLoS ONE 2014. [CrossRef] [PubMed]

3. Barclay, A.N. Membrane proteins with immunoglobulin-like domains-a master superfamily of interaction molecules. Semin. Immunol. 2003, 15, 215-223. [CrossRef]

4. Bezbradica, J.S.; Medzhitov, R. Role of ITAM signaling module in signal integration. Curr. Opin. Immunol. 2012, 24, 58-66. [CrossRef] [PubMed]

5. Engstad, R.E.; Robertsen, B. Recognition of yeast cell wall glucan by Atlantic salmon (Salmo salar L.) macrophages. Dev. Comp. Immunol. 1993, 17, 319-330. [CrossRef]

6. Esteban, M.A.; Meseguer, J. Factors influencing phagocytic response of macrophages from the sea bass (Dicentrarchus labrax L.): An ultrastructural and quantitative study. Anat. Rec. 1997, 248, 533-541. [CrossRef]

7. Frøystad, M.K.; Rode, M.; Berg, T.; Gjøen, T. A role for scavenger receptors in phagocytosis of protein-coated particles in rainbow trout head kidney macrophages. Dev. Comp. Immunol. 1998, 22, 533-549.

8. Li, J.; Barreda, D.R.; Zhang, Y.A.; Boshra, H.; Gelman, A.E.; Lapatra, S.; Tort, L.; Sunyer, J.O. B lymphocytes from early vertebrates have potent phagocytic and microbicidal abilities. Nat. Immunol. 2006, 7, 1116-1124. [CrossRef] [PubMed] 
9. Zhang, Y.A.; Salinas, I.; Li, J.; Parra, D.; Bjork, S.; Xu, Z.; LaPatra, S.E.; Bartholomew, J.; Sunyer, J.O. IgT, a primitive immunoglobulin class specialized in mucosal immunity. Nat. Immunol. 2010, 11, 827-835. [CrossRef] [PubMed]

10. Stuge, T.B.; Wilson, M.R.; Zhou, H.; Barker, K.S.; Bengtén, E.; Chinchar, G.; Miller, N.W.; Clem, L.W. Development and analysis of various clonal alloantigen-dependent cytotoxic cell lines from channel catfish. J. Immunol. 2000, 15, 2971-2977. [CrossRef]

11. Shen, L.; Stuge, T.B.; Bengtén, E.; Wilson, M.; Chinchar, V.G.; Naftel, J.P.; Bernanke, J.M.; Clem, L.W.; Miller, N.W. Identification and characterization of clonal NK-like cells from channel catfish (Ictalurus punctatus). Dev. Comp. Immunol. 2004, 28, 139-152. [CrossRef]

12. Yoshida, S.H.; Stuge, T.B.; Miller, N.W.; Clem, L.W. Phylogeny of lymphocyte heterogeneity: Cytotoxic activity of channel catfish peripheral blood leukocytes directed against allogeneic targets. Dev. Comp. Immunol. 1995, 19, 71-77. [CrossRef]

13. Vallejo, A.N.; Miller, N.W.; Clem, L.W. Phylogeny of immune recognition: Role of alloantigens in antigen presentation in channel catfish immune responses. Immunology 1991, 74, 165-168. [PubMed]

14. Vallejo, A.N.; Miller, N.W.; Harvey, N.E.; Cuchens, M.A.; Warr, G.W.; Clem, L.W. Cellular pathway(s) of antigen processing and presentation in fish APC: Endosomal involvement and cell-free antigen presentation. Dev. Immunol. 1992, 3, 51-65. [CrossRef] [PubMed]

15. Dezfuli, B.S.; Giari, L. Mast cells in the gills and intestines of naturally infected fish: Evidence of migration and degranulation. J. Fish Dis. 2008, 31, 845-852. [CrossRef] [PubMed]

16. Katzenback, B.A.; Belosevic, M. Isolation and functional characterization of neutrophil-like cells, from goldfish (Carassius auratus L.) kidney. Dev. Comp. Immunol. 2009, 33, 601-611. [CrossRef] [PubMed]

17. Chen, K.; Xu, W.; Wilson, M.; He, B.; Miller, N.W.; Bengtén, E.; Edholm, E-E.; Santini, P.A.; Rath, P.; Chiu, A.; et al. Immunoglobulin D enhances immune surveillance by activating antimicrobial, proinflammatory and B cell-stimulating programs in basophils. Nat. Immunol. 2009, 10, 889-898. [CrossRef] [PubMed]

18. Rodríguez-Nunez, I.; Wcisel, D.J.; Litman, G.W.; Yoder, J.A. Multigene families of immunoglobulin domain-containing innate immune receptors in zebrafish: Deciphering the differences. Dev. Comp. Immunol. 2014, 46, 24-34. [CrossRef] [PubMed]

19. Yoder, J.A.; Litman, G.W. The phylogenetic origins of natural killer receptors and recognition: Relationships, possibilities, and realities. Immunogenetics 2011, 63, 123-141. [CrossRef] [PubMed]

20. Montgomery, B.C.; Cortes, H.D.; Mewes-Ares, J.; Verheijen, K.; Stafford, J.L. Teleost IgSF immunoregulatory receptors. Dev. Comp. Immunol. 2011, 25, 1223-1237. [CrossRef] [PubMed]

21. Strong, S.J.; Mueller, M.G.; Litman, R.T.; Hawke, N.A.; Haire, R.N.; Miracle, A.L.; Rast, J.P.; Amemiya, C.T.; Litman, G.W. A novel multigene family encodes diversified variable regions. Proc. Natl. Acad. Sci. USA 1999, 96, 15080-15085. [CrossRef] [PubMed]

22. Yoder, J.A.; Mueller, M.G.; Wei, S.; Corliss, B.C.; Prather, D.M.; Willis, T.; Litman, R.T.; Djeu, J.Y.; Litman, G.W. Immune-type receptor genes in zebrafish share genetic and functional properties with genes encoded by mammalian leukocyte receptor cluster. Proc. Natl. Acad. Sci. USA 2001, 98, 6771-6776. [CrossRef] [PubMed]

23. Cannon, J.P.; Haire, R.N.; Magis, A.T.; Eason, D.D.; Winfrey, K.N.; Hernandez Prada, J.A.; Bailey, K.M.; Jakoncic, J.; Litman, G.W.; Ostrov, D.A. A bony fish immunological receptor of the NITR multigene family mediates allogeneic recognition. Immunity 2008, 29, 228-237. [CrossRef] [PubMed]

24. Yoder, J.A. Form, function and phylogenetics of NITRs in bony fish. Dev. Comp. Immunol. 2009, 33, $135-144$. [CrossRef] [PubMed]

25. Litman, G.W.; Yoder, J.A.; Cannon, J.P.; Haire, R.N. Novel immune-type receptor genes and the origins of adaptive and innate immune recognition. Integr. Comp. Biol. 2003, 43, 331-337. [CrossRef] [PubMed]

26. Litman, G.W.; Hawke, N.A.; Yoder, J.A. Novel immune-type receptor genes. Immunol. Rev. 2001, 181, 250-259. [CrossRef] [PubMed]

27. Stafford, J.L.; Bengtén, E.; Du Pasquier, L.; McIntosh, R.D.; Quiniou, S.M.; Clem, L.W.; Miller, N.W.; Wilson, M. A novel family of diversified immunoregulatory receptors in teleosts is homologous to both mammalian $\mathrm{FC}_{\mathrm{C}}$ receptors and molecules encoded within the leukocyte receptor complex. Immunogenetics 2006, 58, 758-773. [CrossRef] [PubMed]

28. Stafford, J.L.; Bengtén, E.; Du Pasquier, L.; Miller, N.W.; Wilson, M. Channel catfish leukocyte immune-type receptors contain a putative MHC class I binding site. Immunogenetics 2007, 59, 77-91. [CrossRef] [PubMed] 
29. Feng, J.; Call, M.E.; Wucherpfennig, K.W. The assembly of diverse immune receptors is focused on a polar membrane-embedded interaction site. PLoS Biol. 2006. [CrossRef] [PubMed]

30. Kuster, H.; Thompson, H.; Kinet, J.P. Characterization and expression of the gene for the human Fc receptor gamma subunit: Definition of a new gene family. J. Biol. Chem. 1999, 265, 6448-6452.

31. Amoui, M.; Dráberová, L.; Tolar, P.; Dráber, P. Direct interaction of Syk and Lyn protein tyrosine kinases in rat basophilic leukemia cells activated via type I Fc epsilon receptors. Eur. J. Immunol. 1997, 27, 321-328. [CrossRef] [PubMed]

32. Mócsai, A.; Ruland, J.; Tybulewicz, V.L. The SYK tyrosine kinase: A crucial player in diverse biological functions. Nat. Rev. Immunol. 2010, 10, 387-402. [CrossRef] [PubMed]

33. Underhill, D.M.; Goodridge, H.S. The many faces of ITAMs. Trends Immunol. 2007, 28, 66-73. [CrossRef] [PubMed]

34. Holowka, D.; Sil, D.; Torigoe, C.; Baird, B. Insights into immunoglobulin E receptor signaling from structurally defined ligands. Immunol. Rev. 2007, 217, 269-279. [CrossRef] [PubMed]

35. Bakker, A.B.; Wu, J.; Phillips, J.H.; Lanier, L.L. NK cell activation: Distinct stimulatory pathways counterbalancing inhibitory signals. Hum. Immunol. 2000, 61, 18-27. [CrossRef]

36. Lanier, L.L. Up on the tightrope: Natural killer cell activation and inhibition. Nat. Immunol. 2008, 9, 495-502. [CrossRef] [PubMed]

37. Van den Herik-Oudijk, I.E.; Ter Bekke, M.W.; Tempelman, M.J.; Capel, P.J.; van de Winkel, J.G. Functional differences between two Fc receptor ITAM signaling motifs. Blood 1995, 86, 3302-3307. [PubMed]

38. Wu, J.; Cherwinski, H.; Spies, T.; Phillips, J.H.; Lanier, L.L. DAP10 and DAP12 form distinct, but functionally cooperative, receptor complexes in natural killer cells. J. Exp. Med. 2000, 192, 1059-1068. [CrossRef] [PubMed]

39. Lanier, L.L.; Corliss, B.C.; Wu, J.; Leong, C.; Phillips, J.H. Immunoreceptor DAP12 bearing a tyrosine-based activation motif is involved in activating NK cells. Nature 1998, 391, 703-707. [CrossRef] [PubMed]

40. Lanier, L.L.; Corliss, B.; Wu, J.; Phillips, J.H. Association of DAP12 with activating CD94/NKG2C NK cell receptors. Immunity 1998, 8, 693-701. [CrossRef]

41. Yoder, J.A.; Orcutt, T.M.; Traver, D.; Litman, G.W. Structural characteristics of zebrafish orthologs of adaptor molecules that associate with transmembrane immune receptors. Gene 2007, 401, 154-164. [CrossRef] [PubMed]

42. Mewes, J.; Verheijen, K.; Montgomery, B.C.; Stafford, J.L. Stimulatory catfish leukocyte immune-type receptors (IpLITRs) demonstrate a unique ability to associate with adaptor signaling proteins and participate in the formation of homo- and heterodimers. Mol. Immunol. 2009, 47, 318-331. [CrossRef] [PubMed]

43. Takai, T.; Li, M.; Sylvestre, D.; Clynes, R.; Ravetch, J.V. FCR gamma chain deletion results in pleiotrophic effector cell defects. Cell 1994, 76, 519-529. [CrossRef]

44. Kinet, J.P. The gamma-zeta dimers of Fc receptors as connectors to signal transduction. Curr. Opin. Immunol. 1992, 4, 43-48. [CrossRef]

45. Cortes, H.D.; Montgomery, B.C.; Verheijen, K.; García-García, E.; Stafford, J.L. Examination of the stimulatory signaling potential of a channel catfish leukocyte immune-type receptor and associated adaptor. Dev. Comp. Immunol. 2012, 36, 62-73. [CrossRef] [PubMed]

46. Cortes, H.D.; Lillico, D.M.; Zwozdesky, M.A.; Pemberton, J.G.; O'Brien, A.; Montgomery, B.C.; Wiersma, L.; Chang, J.P.; Stafford, J.L. Induction of phagocytosis and intracellular signaling by an inhibitory channel catfish leukocyte immune-type receptor, evidence for immunoregulatory functional plasticity in teleosts. J. Innate Immun. 2014, 6, 435-455. [CrossRef] [PubMed]

47. Ghazizadeh, S.; Bolen, J.B.; Fleit, H.B. Tyrosine phosphorylation and association of Syk with Fc $\gamma$ RII in monocytic THP-1 cells. Biochem. J. 1995, 305, 669-674. [CrossRef] [PubMed]

48. Johnson, S.A.; Pleiman, C.M.; Pao, L.; Schneringer, J.; Hippen, K.; Cambier, J.C. Phosphorylated immunoreceptor signaling motifs (ITAMs) exhibit unique abilities to bind and activate Lyn and Syk tyrosine kinases. J. Immunol. 1995, 155, 4596-4603. [PubMed]

49. Crowley, M.T.; Costello, P.S.; Fitzer-Attas, C.J.; Turner, M.; Meng, F.; Lowell, C.; Tybulewicz, V.L.; DeFranco, A.L. A critical role for Syk in signal transduction and phagocytosis mediated by Fcgamma receptors on macrophages. J. Exp. Med. 1997, 186, 1027-1039. [CrossRef] [PubMed] 
50. Kiefer, F.; Brumell, J.; Al-Alawi, N.; Latour, S.; Cheng, A.; Veillette, A.; Grinstein, S.; Pawson, T. The Syk protein tyrosine kinase is essential for Fcgamma receptor signaling in macrophages and neutrophils. Mol. Cell Biol. 1998, 18, 4209-4220. [CrossRef] [PubMed]

51. Ninomiya, N.; Hazeki, K.; Fukui, Y.; Seya, T.; Okada, T.; Hazeki, O.; Ui, M. Involvement of phosphatidylinositol 3-kinase in Fc $\gamma$ receptor signaling. J. Biol. Chem. 1994, 269, 22732-22737. [PubMed]

52. Patel, J.C.; Hall, A.; Caron, E. Vav regulates activation of Rac but not Cdc42 during FcgammaR-mediated phagocytosis. Mol. Biol. Cell 2002, 13, 1215-1226. [CrossRef] [PubMed]

53. Hoppe, A.D.; Swanson, J.A. Cdc42, Rac1, and Rac2 display distinct patterns of activation during phagocytosis. Mol. Biol. Cell 2004, 15, 3509-3519. [CrossRef] [PubMed]

54. Hall, A.B.; Gakidis, M.A.M.; Glogauer, M.; Wilsbacher, J.L.; Gao, S.; Wojciech, S.; Brugge, J.S. Requirements for Vav guanine nucleotide exchange factors and Rho GTPases in FcgammaR- and complement-mediated phagocytosis. Immunity 2006, 24, 305-316. [CrossRef] [PubMed]

55. May, R.C.; Caron, E.; Hall, A.; Machesky, L.M. Involvement of the Arp2/3 complex in phagocytosis mediated by FcgammaR or CR3. Nat. Cell Biol. 2000, 2, 246-248. [PubMed]

56. Park, H.; Cox, D. Cdc42 regulates Fcgamma receptor-mediated phagocytosis through the activation and phosphorylation of Wiskott-Aldrich syndrome protein (WASP) and neural WASP. Mol. Biol. Cell 2009, 20, 4500-4508. [CrossRef] [PubMed]

57. Lillico, D.M.; Zwozdesky, M.A.; Pemberton, J.G.; Deutscher, J.M.; Jones, L.O.; Chang, J.P.; Stafford, J.L. Teleost leukocyte immune-type receptors activate distinct phagocytic modes for target acquisition and engulfment. J. Leukoc. Biol. 2015, 98, 235-248. [CrossRef] [PubMed]

58. Vivier, E.; Daeron, M. Immunoreceptor tyrosine-based inhibition motifs. Immunol. Today 1997, 18, $286-291$. [CrossRef]

59. Burshtyn, D.N.; Yang, W.; Yi, T.; Long, E.O. A novel phosphotyrosine motif with a critical amino acid at position-2 for the SH2 domain-mediated activation of the tyrosine phosphatase SHP-1. J. Biol. Chem. 1997, 272, 13066-13072. [CrossRef] [PubMed]

60. Burshtyn, D.N.; Lam, A.S.; Weston, M.; Gupta, N.; Warmerdam, P.A.; Long, E.O. Conserved residues amino-terminal of cytoplasmic tyrosines contribute to the SHP-1-mediated inhibitory function of killer cell Ig-like receptors. J. Immunol. 1999, 162, 897-902. [PubMed]

61. Long, E.O. Regulation of immune responses through inhibitory receptors. Annu. Rev. Immunol. 1999, 17, 875-904. [CrossRef] [PubMed]

62. Ravetch, J.V.; Lanier, L.L. Immune Inhibitory Receptor. Science 2000, 290, 84-89. [CrossRef] [PubMed]

63. Sidorenko, S.P.; Clark, E.A. The dual-function CD150 receptor subfamily: The viral attraction. Nat. Immunol. 2003, 4, 19-24. [CrossRef] [PubMed]

64. Montgomery, B.C.; Mewes, J.; Davidson, C.; Burshtyn, D.N.; Stafford, J.L. Cell surface expression of channel catfish leukocyte immune-type receptors (IpLITRs) and recruitment of both Src homology 2 domain-containing protein tyrosine phosphatase (SHP)-1 and SHP-2. Dev. Comp. Immunol. 2009, 33, 570-582. [CrossRef] [PubMed]

65. Montgomery, B.C.; Cortes, H.D.; Burshtyn, D.N.; Stafford, J.L. Channel catfish leukocyte immune-type receptor mediated inhibition of cellular cytotoxicity is facilitated by SHP-1-dependent and -independent mechanisms. Dev. Comp. Immunol. 2012, 37, 151-163. [CrossRef] [PubMed]

66. Songyang, Z.; Shoelson, S.E.; McGlade, J.; Olivier, P.; Pawson, T.; Bustelo, X.R. Specific motifs recognized by the SH2 domains of Csk, 3BP2, fps/fes, GRB-2, HCP, SHC, Syk, and Vav. Mol. Cell. Biol. 1994, 14, 2777-2785. [CrossRef] [PubMed]

67. Okada, M.; Nada, S.; Yamanashi, Y.; Yamamoto, T.; Nakagawa, H. Csk: A protein-tyrosine kinase involved in regulation of Src family kinases. J. Biol. Chem. 1991, 266, 24249-24252. [PubMed]

68. Chong, Y-P.; Mulhern, T.D.; Cheng, H.-C. C-terminal kinase (Csk) and CSK-homologous kinase (CHK)-endogenous negative regulators of Src-family protein kinases. Growth Factors 2005, 23, $233-244$. [CrossRef] [PubMed]

69. Verbrugge, A.; Rijkers, E.S.K.; de Ruiter, T.; Meyaard, L. Leukocyte associated Ig-like receptor-1 has SH-2 domain-containing phosphatase independent function and recruits C-terminal Src kinase. Eur. J. Immmunol. 2006, 36, 190-198. [CrossRef] [PubMed] 
70. Sayos, J.; Martinez-Barriocanal, A.; Kitzig, F.; Bellon, T.; Lopez-Botet, M. Recruitment of C-terminal Src kinase by the leukocyte inhibitory receptor CD85j. Biochem. Biophys. Res. Commun. 2004, 324, 640-647. [CrossRef] [PubMed]

71. Àlvarez-Errico, D.; Sayós, J.; López-Botet, N. The IREM-1 (CD300f) inhibitory receptor associates with the p85 $\alpha$ subunit of phosphoinositide 3-kinase. J. Immunol. 2007, 178, 808-816. [CrossRef] [PubMed]

72. Izawa, K.; Kitaura, J.; Yamanishi, Y.; Matsuoka, T.; Kaitani, A.; Sugiuchi, M.; Takahashi, M.; Maehara, A.; Enomoto, Y.; Oki, T.; et al. An activating and inhibitory signal from an inhibitory receptor LMIR3/CLM-1: LMIR3 augments lipopolysaccharide response through association with FCR $\gamma$ in mast cells. J. Immunol. 2009, 183, 925-936. [CrossRef] [PubMed]

73. Newman, P.J.; Newman, D.K. Signal transduction pathways mediated by PECAM-1: New roles for an old molecule in platelet and vascular cell biology. Arterioscler. Thromb. Vasc. Biol. 2003, 23, 953-964. [CrossRef] [PubMed]

74. Faure, M.; Long, E.O. KIR2DL4 (CD158d), an NK cell-activating receptor with inhibitory potential. J. Immunol. 2002, 168, 6208-6214. [CrossRef] [PubMed]

75. Rajagopalan, S.; Fu, J.; Long, E.O. Cutting edge: Induction of IFN-gamma production but not cytotoxicity by the killer cell Ig-like receptor KIR2DL4 (CD185d) in resting NK cells. J. Immunol. 2001, 167, 1877-1881. [CrossRef] [PubMed]

76. Kikuchi-Maki, A.; Yusa, S.; Catina, T.L.; Campbell, K.S. KIR2DL4 is an IL-2 regulated NK cell receptor that exhibits limited expression in humans but triggers strong IFN gamma production. J. Immunol. 2003, 171, 3415-3425. [CrossRef] [PubMed]

77. Kikuchi-Maki, A.; Catina, T.L.; Campbell, K.S. Cutting edge: KIR2DL4 transduces signals into human NK cells through association with the Fc receptor gamma protein. J. Immunol. 2005, 174, 3859-3863. [CrossRef] [PubMed]

78. Zhang, Y.; Zhou, Y.; Yang, Q.; Mu, C.; Duan, E.; Chen, J.; Yang, M.; Xia, P.; Cui, B. Ligation of Fc gamma receptor IIB enhances levels of antiviral cytokine in response to PRRSV infection in vitro. Vet. Microbiol. 2012, 160, 473-480. [CrossRef] [PubMed]

79. Blank, U.; Launay, P.; Benhamou, M.; Monteiro, R.C. Inhibitory ITAMs as novel regulators of immunity. Immunol. Rev. 2009, 232, 59-71. [CrossRef] [PubMed]

80. Ivashkiv, L.B. How ITAMs inhibit signaling. Sci. Signal. 2011. [CrossRef] [PubMed]

81. Pfirsch-Maisonnas, S.; Aloulou, M.; Xu, T.; Claver, J.; Kanamaru, T.; Tiwari, M.; Launay, P.; Monteiro, R.C.; Blank, U. Inhibitory ITAM signaling traps activating receptors with the phosphatase SHP-1 to form polarized “inhibisome" clusters. Sci. Signal. 2011. [CrossRef] [PubMed]

82. Chemnitz, J.M.; Parry, R.V.; Nichols, K.E.; June, C.H.; Riley, J.L. SHP-1 and SHP-2 associate with immunoreceptor tyrosine-based switch motif of programmed death 1 upon primary human $\mathrm{T}$ cell stimulation, but only receptor ligation prevents T cell activation. J. Immunol. 2004, 173, 945-954. [CrossRef] [PubMed]

83. Shlapatska, L.M.; Mikhalap, S.V.; Berdova, A.G.; Zelensky, O.M.; Yun, T.J.; Nichols, K.E.; Clark, E.A.; Sidorenko, S.P. CD150 association with either the SH2 containing inositol phosphatase or the SH2-containing protein tyrosine phosphatase is regulated by the adaptor protein SH2D1A. J. Immunol. 2001, 166, 5480-5487. [CrossRef] [PubMed]

84. Mikhalap, S.V.; Shlapatska, L.M.; Berdova, A.G.; Law, C.L.; Clark, E.A.; Sidorenko, S.P. CDw150 associates with src-homology 2-containing inositol phosphatase and modulates CD96-mediated apoptosis. J. Immunol. 1999, 15, 5719-5727.

85. Aoukaty, A.; Tan, R. Association of the X-linked lymphoproliferative disease gene product SAP/SH2D1A with 2B4, a natural killer cell-activating molecule, is dependent on phosphoinositide 3-kinase. J. Biol. Chem. 2002, 277, 13331-13337. [CrossRef] [PubMed]

86. Li, C.; Iosef, C.; Jia, C.Y.; Han, V.K.; Li, S.S. Dual functional roles for the X-linked lymphoproliferative syndrome gene product SAP/SH2D1A in signaling through the signaling lymphocyte activation molecule (SLAM) family of immune receptors. J. Biol. Chem. 1993, 278, 3852-3859. [CrossRef] [PubMed]

87. Brummer, T.; Schmitz-Peiffer, C.; Daly, R.J. Docking proteins. FEBS J. 2010, 277, 4356-4369. [CrossRef] [PubMed]

88. Belov, A.A.; Mohammadi, N. Grb2, a double-edged sword of receptor tyrosine kinase signaling. Sci. Signal. 2012. [CrossRef] [PubMed] 
89. Gotoh, N. Regulation of growth factor signaling by FRS2 family docking/scaffold adaptor proteins. Cancer Sci. 2008, 99, 1319-1325. [CrossRef] [PubMed]

90. Gu, H.; Saito, K.; Klaman, L.D.; Shen, J.; Fleming, T.; Wang, Y.; Pratt, J.C.; Lin, G.; Lim, B.; Kinet, J.P.; et al . Essential role for Gab2 in the allergic response. Nature 2001, 412, 186-190. [CrossRef] [PubMed]

91. Bohdanowicz, M.; Cosío, G.; Backer, J.M.; Grinstein, S. Class I and class III phosphoinositide 3-kinases are required for actin polymerization that propels phagosomes. J. Cell Biol. 2010, 191, 999-1012. [CrossRef] [PubMed]

92. Gu, H.; Botelho, R.J.; Yu, M.; Grinstein, S.; Neel, B.G. Critical role for scaffolding adapter Gab2 in Fc gamma R-mediated phagocytosis. J. Cell Biol. 2003, 161, 1151-1161. [CrossRef] [PubMed]

93. Li, W.; Nishimura, R.; Kashishian, A.; Batzer, A.G.; Kim, W.J.; Cooper, J.A.; Schlessinger, J. A new function for a phosphotyrosine phosphatase: Linking GRB2-Sos to a receptor tyrosine kinase. Mol. Cell. Biol. 1994, 12, 509-517. [CrossRef]

94. Bennett, A.M.; Tang, T.L.; Sugimoto, S.; Walsh, C.T.; Neel, B.G. Protein-tyrosine phosphatase SHPTP2 couples platelet-derived growth factor receptor $\beta$ to Ras. Proc. Natl. Acad. Sci. USA 1991, 91, 7335-7339. [CrossRef]

95. Gu, H.; Botelho, R.J.; Yu, M.; Grinstein, S.; Neel, B.G. Critical role for scaffolding adapter Gab2 in Fc $\gamma$ R-mediated phagocytosis. J. Cell. Biol. 2003, 161, 1151-1161. [CrossRef] [PubMed]

96. Lowenstein, E.J.; Daly, R.J.; Batzer, A.G.; Li, W.; Margolis, B.; Lammers, R.; Ullrich, A.; Skolnik, E.Y.; Bar-Sagi, D.; Schlessinger, J. The SH2 and SH3 domain containing protein GRB2 links receptor tyrosine kinases to ras signaling. Cell 1992, 70, 431-442. [CrossRef]

97. Simon, M.A.; Bowtell, D.D.; Dodson, G.S.; Laverty, T.R.; Rubin, G.M. Ras1 and a putative guanine nucleotide exchange factor perform crucial steps in signaling by the sevenless protein tyrosine kinase. Cell 1991, 67, 701-716. [CrossRef]

98. Li, N.; Batzer, A.; Daly, R.; Yajnik, V.; Skolnik, E.; Chardin, P.; Bar-Sagi, D.; Margolis, B.; Schlessinger, J. Guanine-nucleotide-releasing factor hSos1 binds to Grb2 and links receptor tyrosine kinases to Ras signalling. Nature 1993, 363, 85-88. [CrossRef] [PubMed]

99. Araki, N.; Johnson, M.T.; Swanson, J.A. A role for phosphoinositide 3-kinase of macropinocytosis and phagocytosis by macrophages. J. Cell. Biol. 1996, 135, 1249-1260. [CrossRef] [PubMed]

100. Cox, D.; Tseng, C.C.; Bjekic, G.; Greenberg, S. A requirement for phosphatidylinositol 3-kinase in pseudopod extension. J. Biol. Chem. 1999, 274, 1240-1247. [CrossRef] [PubMed]

101. Katzav, S. Vav1: A hematopoietic signal transduction molecule involved in human malignancies. Int. J. Biochem. Cell. Biol. 2009, 41, 1245-1248. [CrossRef] [PubMed]

102. Schmitter, T.; Pils, S.; Sakk, V.; Frank, R.; Fischer, K-D.; Hauck, C.R. The granulocyte receptor carcinoembryonic antigen-related cell adhesion molecule 3 (CEACAM3) directly associates with Vav to promote phagocytosis of human pathogens. J. Immunol. 2007, 178, 3797-3805. [CrossRef] [PubMed]

103. Pils, S.; Kopp, K.; Peterson, L.; Delgado Tascón, J.; Nyffenegger-Jann, N.J.; Hauck, C.R. The adaptor molecule Nck localizes the WAVE complex to promote actin polymerization during CEACAM3-mediated phagocytosis of bacteria. PLoS ONE 2012, 7, e32808. [CrossRef] [PubMed]

104. Takenawa, T.; Suetsugu, S. The WASP-WAVE protein network, connecting the membrane to the cytoskeleton. Nat. Rev. Nol. Cell Biol. 2007, 8, 37-48. [CrossRef] [PubMed]

105. Frese, S.; Schubert, W.D.; Findeis, A.C.; Marquardt, T.; Roske, Y.S.; Stradal, T.E.; Heinz, D.W. The phosphotyrosine peptide binding specificity of Nck1 and Nck2 Src homology 2 domains. J. Biol. Chem. 2006, 281, 18236-18245. [CrossRef] [PubMed]

106. Mendoza, M.C. Phosphoregulation of the WAVE regulatory complex and signal integration. Semin. Cell Dev. Biol. 2013, 24, 272-279. [CrossRef] [PubMed]

107. Wang, J.; Wu, Y.; Hu, H.; Wang, W.; Lu, Y.; Mao, H.; Liu, X.; Liu, Z.; Chen, B.G. Syk protein tyrosine kinase involves PECAM-1 signaling through tandem immunotyrosine inhibitory motifs in human THP-1 macrophages. Cell. Immunol. 2011, 279, 39-44. [CrossRef] [PubMed]

108. Rougerie, P.; Miskolci, V.; Cox, D. Generation of membrane structures during phagocytosis and chemotaxis of macrophages: Role and regulation of the actin cytoskeleton. Immunol. Rev. 2013, 256, 222-239. [CrossRef] [PubMed]

109. Beemiller, P.; Zhang, Y.; Mohan, S.; Levinsohn, E.; Gaeta, I.; Hoppe, A.D.; Swanson, J.A. A Cdc42 activation cycle coordinated by PI 3-kinase during Fc receptor-mediated phagocytosis. Mol. Biol. Cell. 2010, 21, 470-480. [CrossRef] [PubMed] 
110. Niedergang, F.; Colucci-Guyon, E.; Dubois, T.; Raposo, G.; Chavrier, P. ADP ribosylation factor 6 is activated and controls membrane delivery during phagocytosis in macrophages. J. Cell Biol. 2003, 161, 1143-1150. [CrossRef] [PubMed]

111. Cox, D.; Lee, D.J.; Dale, B.M.; Calafat, J.; Greenberg, S. A Rab11-containing rapidly recycling compartment in macrophages that promotes phagocytosis. Proc. Natl. Acad. Sci. USA 2000, 97, 680-685. [CrossRef] [PubMed]

112. Braun, V.; Fraisier, V.; Raposo, G.; Hurbain, I.; Sibarita, J.B.; Chavrier, P.; Galli, T.; Niedergang, F. TI-VAMP/VAMP7 is required for optimal phagocytosis of opsonised particles in macrophages. EMBO J. 2004, 23, 4166-4176. [CrossRef] [PubMed]

113. Lee, W.L.; Mason, D.; Schreiber, A.D.; Grinstein, S. Quantitative analysis of membrane remodeling at the phagocytic cup. Mol. Biol. Cell 2007, 18, 2883-2892. [CrossRef] [PubMed]

114. Bhattacharyya, R.P.; Reményi, A.; Yeh, B.J.; Lim, W.A. Domains, motifs, and scaffolds: The role of modular interactions in the evolution and wiring of cell signaling circuits. Annu. Rev. Biochem. 2006, 75, 655-680. [CrossRef] [PubMed]

(C) 2016 by the authors; licensee MDPI, Basel, Switzerland. This article is an open access article distributed under the terms and conditions of the Creative Commons by Attribution (CC-BY) license (http://creativecommons.org/licenses/by/4.0/). 